\title{
EVALUATING THE EFFECTS OF MINDFULNESS-BASED STRESS REDUCTION ON COGNITIVE FUNCTION AND QUALITY OF LIFE IN NONDEMENTED OLDER ADULTS: A PILOT STUDY
}

\author{
by \\ Sasha Mallya \\ Bachelor of Arts (Honours), Ryerson University, Toronto, Ontario, 2010 \\ A thesis \\ presented to Ryerson University \\ in partial fulfillment \\ of the requirements for the degree of \\ Master of Arts \\ in the Program of \\ Psychology
}

Toronto, Ontario, Canada, 2014

(C) Sasha Mallya 2014 


\section{AUTHOR'S DECLARATION FOR ELECTRONIC SUBMISSION OF A THESIS}

I hereby declare that I am the sole author of this thesis. This is a true copy of the thesis, including any required final revisions, as accepted by my examiners.

I authorize Ryerson University to lend this thesis to other institutions or individuals for the purpose of scholarly research

I further authorize Ryerson University to reproduce this thesis by photocopying or by other means, in total or in part, at the request of other institutions or individuals for the purpose of scholarly research.

I understand that my thesis may be made electronically available to the public. 
Evaluating The Effects of Mindfulness--Based Stress Reduction on Cognitive Function and Quality of Life in Nondemented Older Adults: A Pilot Study

Master of Arts 2014

Sasha Mallya

Psychology, Ryerson University

\begin{abstract}
Adults over the age of 65 years are now the fastest growing segment of the Canadian population. Although individual differences exist, aging is commonly associated with impairments in executive function. The present pilot study investigated the effectiveness of a mindfulness-"based stress reduction (MBSR) program on improving executive functioning in older adults, while additionally decreasing perceived stress and improving psychological wellbeing. It was hypothesized that compared with an active control group, the MBSR group would display significant improvements in executive functioning, mood, self-esteem, and perceived stress. Participants were randomly assigned to either MBSR $(n=40)$ or an active control group $(n=32)$. Results suggest that MBSR is associated with significantly enhanced quality of life compared with the control condition. No additional significant results were found. A full-scale study will be necessary to clarify the present results.
\end{abstract}




\section{Acknowledgements}

First and foremost, I would like to express my deep appreciation to my supervisor, Dr. Alexandra J. Fiocco, for providing me with ongoing and invaluable support at every stage of this project. I would also like to thank Kathryn Curtis, Robin Hurlow, and Kirstin Bindseil for being such amazing group facilitators and helping us impart mindfulness to the community. Special thanks to Jennifer Boone, Tharshalah Pathmaseelan, Prudence Leung, and Mitra Farzaneh who worked tirelessly on data collection.

I would like to thank Dr. Candice Monson for providing wisdom and insight throughout the development of the project, and Dr. Lixia Yang for agreeing to be my external reviewer. I feel grateful to have such an esteemed committee. Additionally, I would like to thank all of my wonderful participants, who truly illuminated this project.

Finally, I would like to thank my mother, Bharati Mallya, the rest of my family and incredible friends, and my supportive cohort, who inspire me every day. 


\section{Dedication}

For all of the hard work - this thesis is dedicated to me. 


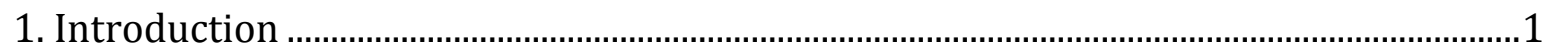

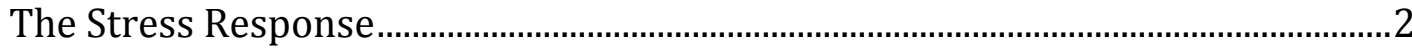

Stress and Executive Function....................................................................................

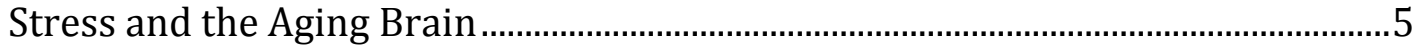

Individual Differences in Stress and Aging.............................................................

Mindfulness as a Potential Intervention for Cognitive Decline ...............................9

Objectives and Hypotheses ...................................................................................... 15

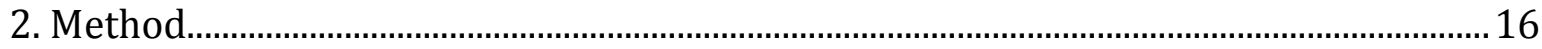

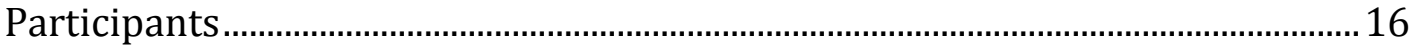

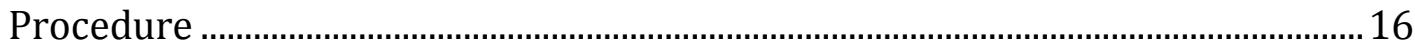

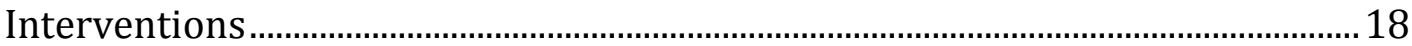

Mindfulness-based stress reduction (MBSR) ………………………........ 19

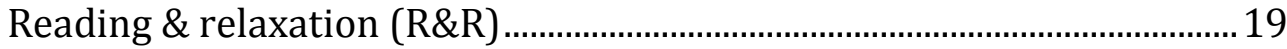

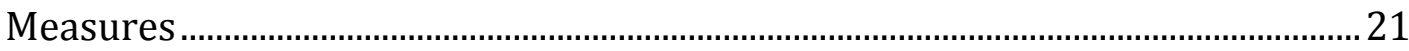

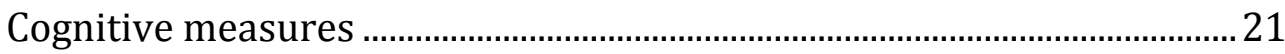

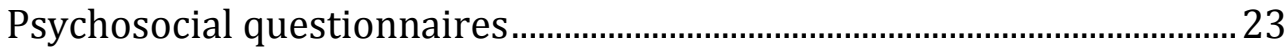

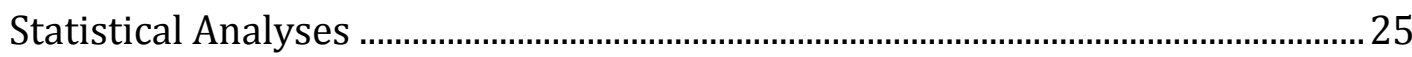

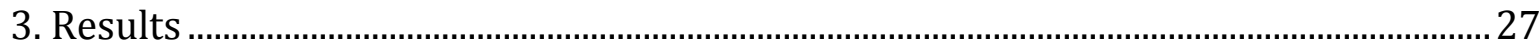

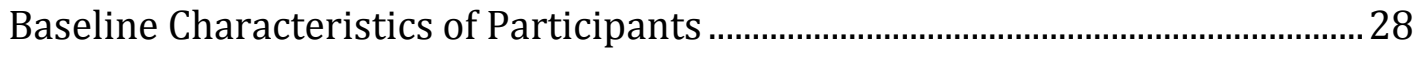

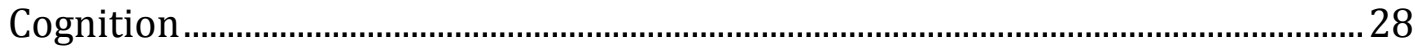

Psychosocial Questionnaires...............................................................................

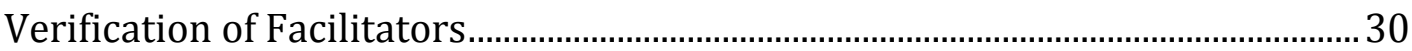

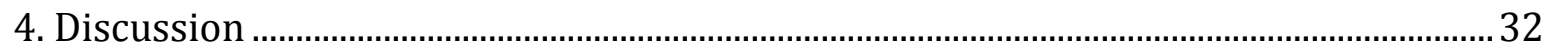

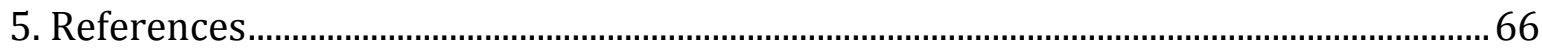




\section{List of Tables}

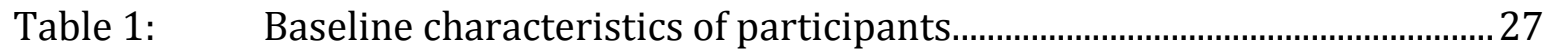

Table 2: $\quad$ Cognitive outcomes, by group and time........................................................2

Table 3: $\quad$ Psychosocial outcomes, by group and time.................................................... 31 


\section{List of Figures}

Figure 1: $\quad$ CONSORT diagram showing participant flow and distribution .................18 


\section{List of Appendices}

Appendix A: Telephone Script for Recruiting ……………………..................................... 39

Appendix B: Phone Screening Questionnaire …………………………………………... 42

Appendix C: Ryerson University Consent Agreement ..................................................... 48

Appendix D: MBSR Protocol............................................................................................... 53

Appendix E: Reading \& Relaxation Protocol ……………………………………………....5

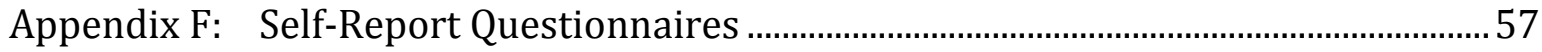

Appendix G: Adherence Checklist......................................................................................... 65 
Evaluating the Effects of Mindfulness-Based Stress Reduction on Cognitive Function and Quality of Life in Nondemented Older Adults: A Pilot Study

The Canadian population is aging; adults over the age of 65 are now the fastest growing segment of our population (Statistics Canada, 2010) and according to a 2002 Health Canada report, one in five Canadians will have reached the age of 65 by 2026 (Health Canada, 2002). An aging population will inevitably affect Canada's healthcare system, labour markets, and public finances (Health Canada, 2002). In order to lessen the financial burden on Canadian society, efforts focused on maintaining older adults' physical and mental health are imperative.

One of the most significant consequences of aging is cognitive decline, with decays most often seen in memory, executive functions, processing speed, and reasoning (Deary et al., 2009). A decline in cognitive function is associated with reductions in functional status, independence, and overall quality of life (QOL; Ball et al., 2002). Executive functioning in particular is important in maintaining QOL because it enables individuals to successfully engage in independent, purposive, and self-serving behavior (Lezak, 1995); as long as executive functioning is intact, individuals with substantial cognitive impairment can still continue to be independent and productive (Lezak, Howieson, \& Loring, 2004).

Although it is often thought that cognitive decline is an inevitable byproduct of aging, individual differences exist that can either protect the individual from this process, or increase the likelihood that an individual will experience deterioration in cognitive processes. For instance, working or volunteering, engaging in moderate to vigorous weekly exercise, and drinking less than one alcoholic beverage per day are a 
few examples of factors that promote cognitive maintenance in late life (Yaffe et al., 2009). The purpose of the current study is to test an intervention that is hypothesized to improve cognitive performance in a sample of healthy older adults and enhance overall quality of life. One of the most heavily researched mediators between aging and cognitive decline is stress exposure (Garrido, 2011).

\section{The Stress Response}

When an individual perceives an event to be stressful, a series of physiological events are initiated, with the purpose of mobilizing the individual and allowing the individual to cope with the stressor. The two primary stress response systems are the sympathetic-adrenal-medullary (SAM) system and the hypothalamic--pituitary.-. adrenal (HPA) axis (Herman \& Cullinan, 1997). Activation of these stress response systems can be described as occurring in two waves. The response of the SAM system is the primary, fast acting wave that initiates the fight-or-flight response. Sympathetic activation of the adrenal medulla leads to almost immediate secretion of norepinephrine (NE) and epinephrine (EPI) (Thierry et al., 1968), which leads to increased heart rate, respiration, blood flow, and blood pressure, and simultaneous suppression of digestion, growth, and the reproductive and immune systems (Sapolsky, 1999).

The second, slower wave consists of HPA axis activation, which takes minutes to respond but remains activated for a prolonged period lasting from minutes to hours (McEwen \& Sapolsky, 1995). Activation of the HPA axis begins with the secretion of corticotropin-releasing hormone (CRH; Herman \& Cullinan, 1997) from the hypothalamus, which stimulates the anterior pituitary gland to secrete and 
release adrenocorticotropin hormone (ACTH), which enters the bloodstream and activates the adrenal cortex, resulting in the culmination of glucocorticoids (GC; Hennessy \& Levine, 1979), or cortisol in humans. Cortisol raises heart rate and blood pressure, which in turn increases the availability of blood glucose (i.e., energy) to the muscles (Sapolsky, 1999). Cortisol is also vital for turning the HPA system off through a negative feedback inactivation system, signaling the hypothalamus and adrenal glands to decrease hormone secretion.

Although this biological stress response system is adaptive under conditions of acute stress, excessive exposure to these stress hormones can affect the efficiency of the HPA axis. Studies examining caregivers, who typically experience prolonged significant physical, psychosocial, and monetary stress (Pinquart \& Sorensen, 2003; Schulz \& Martire, 2004), provide evidence for the biological effects of chronic stress. For instance, highly stressed individuals can show increased levels of salivary cortisol throughout the day (Bauer et al., 2000; Gallagher-Thompson et al., 2006; Vedhara et al., 1999) and increased plasma NE levels (Mills et al., 1997). Compared with healthy controls, caregivers have also been found to have alterations in HPA functioning, demonstrated by lower dehydroepiandrosterone sulfate (DHEAS; the metabolite of dehydroepiandrosterone [DHEA], a cortisol antagonist), higher cortisol-to-DHEAS ratio, and less sensitivity to the HPA negative feedback loop (Jeckel et al., 2010). These hormonal changes that result from chronic perceived stress can have many detrimental effects on the body, resulting in compromised immune function (Mausbach et al., 2008), increased blood pressure (von Kanel et al., 2008), increased depressive symptomatology (Bergdahl \& Bergdahl, 2002), decreased overall wellbeing (Cohen, 1986), and impaired brain function (Lyons, Lopez, Yang, \& 
Schatzberg, 2000).

\section{Stress and Executive Function}

In addition to exerting effects on the body, stress hormones also affect cognitive functioning. One area of the brain that is known to be susceptible to stress hormone exposure is the prefrontal cortex (PFC; Starcke \& Brand, 2012). The PFC is the brain region that is thought to govern executive functioning. Executive functions are comprised of a number of more basic processes such as working memory, cognitive flexibility (Williams, Suchy, \& Rau, 2009), and verbal fluency (Kemper \& McDowd, 2008). In day-to-day life, these processes manifest as the ability to solve novel problems, modify behavior, generate strategies for completing goal-directed behavior, and govern more primary behavioral and emotional needs (Williams et al., 2009).

Chronic stress appears to result in a number of negative consequences in the PFC. Animal studies have demonstrated that exposure to chronic stress results in glucocorticoid receptor down-regulation in the PFC (Sapolsky, Krey, \& McEwen, 1984). Other neurotransmitters such as glutamate (Jedema \& Moghaddam, 1994) and dopamine (Mizoguchi et al., 2000) are also stress-sensitive and contribute to cognitive decline (e.g., working memory impairment). Human studies examining the relationship between stress and PFC functioning have largely been conducted in younger adults, but generally produce consistent findings that stress impairs PFC functioning, as demonstrated by impairments in working memory (Lewis, Nikolova, Chang, \& Weekes, 2008), selective attention (Skosnik, Chatterton, Swisher, \& Park, 2000), and decision-making (Porcelli \& Delgado, 2009). Fortunately, these consequences are potentially reversible in humans upon removal of the stressor (Liston, McEwen, \& Casey, 2009). 
Although almost no experimental research has been conducted examining the relationship between stress and PFC functioning in older adults, one study demonstrated that in a sample of 1140 adults aged 50 to 70 years, higher levels of cortisol were associated with worse performance on measures of language, processing speed, executive function, verbal memory and learning, and visual memory (Lee et al., 2007). Related research has shown that there is a clear reduction of dendritic branching of PFC neurons with age (Coffey, 2000), possibly due to the preferential distribution of glucocorticoid receptors in the PFC (Meaney \& Aitken, 1985). Indeed, over time, the frontal lobes deteriorate earlier and more severely than other brain areas even in normal aging (Haug et al., 1983).

Declines in executive function have a number of detrimental effects on an individual's functioning. For instance, a number of cross-sectional studies have suggested that otherwise healthy community-dwelling older adults who perform poorly on tests of executive function have more difficulty completing instrumental activities of daily living than do older adults without executive impairment (CahnWeiner, Malloy, Boyle, Marran, \& Salloway, 2000; Carlson et al., 1999; \& Grigsby, Kaye, Baxter, Shetterly, \& Hamman, 1998). Longitudinal studies have corroborated these results, finding that executive function impairment is a reliable predictor of functional decline (Royall, Palmer, Chiodo, \& Polk, 2004; Wang et al., 2002). Thus, executive dysfunction is an important contributor to quality of life status in older adults and stress reduction techniques may improve quality of life.

\section{Stress and the Aging Brain}

Although stress is detrimental to the brain during any stage of the lifespan, older adults seem particularly susceptible to its effects due to normal age-related changes in 
neuroendrocrine function and metabolic function. For instance, aging adults typically experience a substantial increase in adrenocorticotrophic hormone (ACTH) compared with younger adults (Luz et al., 2003). Additionally, age is associated with increased levels of NE (Seals \& Esler, 2000), and changes in NE metabolism (Ida et al., 1982). Older adults also typically demonstrate decreased HPA sensitivity to negative feedback from glucocorticoids (Otte et al., 2005) and a decrease in DHEA and DHEAS (Svec, 1997). Thus, another reason that older adults in particular are susceptible to cortisol-related cognitive impairment is because the protective effects of DHEA and DHEAS are reduced (Carlson \& Sherwin, 1998). These hormones play a central role in the physiological response to stress, and imbalances in cortisol in particular are shown to associate with cognitive impairment in older adults (Lupien et al., 1994).

Age--related cognitive decline and stress-related cognitive decline also share common factors. In rodents, exposure to chronic stress has been shown to cause impairments in set-shifting tasks (a PFC-dependent task); these deficits correlate with morphological changes in prefrontal neurons (Liston et al., 2006). Similarly, aged rats that are impaired on the same set-shifting task perform normally on tasks independent of the mPFC (Barense et al., 2002), suggesting that stress and aging may target overlapping prefrontal neurons. Moreover, the neuron loss seen in an aging brain can be replicated by exposing animals with an otherwise healthy brain to excessive stress hormones (Sapolsky, 1996). Other researchers have found that aged rats that are surgically or behaviourally manipulated to experience reduced lifelong GC exposure also display neuron loss and associated cognitive deficits (Landfield, Baskin, \& Pitler, 1982; Meaney, Aitken, Bhatnager, Vanberkel, \& Sapolsky, 1988; Sapolsky, 1992). 
Issa and colleagues (Issa, Rowe, Gauthier, \& Meaney, 1990) extended these findings by testing spatial memory in aged rats. As expected, older rats, on average, performed worse than younger rats, but there was a subset of aged rats that showed no age -.related impairment. When the 'unimpaired' aged rats were compared with the impaired rats, the unimpaired group showed normal GC secretion compared with their impaired counterparts (Issa et al., 1990). This was one of the first animal studies to suggest that there are individual differences in GC secretion and that this difference may significantly affect age-"-associated cognitive decline. This finding was later observed in a cohort of healthy older adults. In a longitudinal study by Lupien and colleagues (1998), only 38\% of the cohort showed an increase in basal cortisol secretion over a 4-year period, with the remaining sample displaying a decline or maintenance of cortisol levels over the years. Interestingly, individuals who demonstrated increasing levels of cortisol over 4 years also showed subsequent cognitive deficits (Lupien et al., 1998), whereas those who displayed moderate or decreasing levels of cortisol over time did not experience these deficits.

\section{Individual Differences in Stress and Aging}

Increasing scientific recognition of the variability in cognitive function with age has led researchers to question the inevitability of age-related cognitive decline (McEwen, de Leon, Lupien, \& Meaney, 1999). Although it is well documented that cortisol hypersecretion is associated with aging (Otte et al., 2005), the aforementioned landmark study by Lupien and colleagues (1998) demonstrates that an increase in basal cortisol levels does not inevitably occur in all older adults.

Another factor that may explain marked individual differences in older adults' susceptibility to stress is the interaction between an individual's environment and his 
or her unique predispositions (McEwen \& Stellar, 1993). For instance, psychological resilience factors, environmental conditions, and biological mechanisms have all been found to affect vulnerability to maladaptive stress responses. Resilience is defined as the ability to continuously adapt successfully to different stressors (Feder, Nestler, \& Charney, 2009). Thus, a resilient individual continues to demonstrate adaptive physiological, psychological, and cognitive responses despite exposure to a number of stressors. Several factors have been found to be associated with stress resilience, including psychosocial factors such as positive emotions and social support (Bonanno, 2004), task-oriented coping (Penley, Tomaka, \& Wiebe, 2002), and openness to experience (Williams, Rau, Cribbet, \& Gunn, 2009).

Openness to experience is a broad personality domain that is related to active imagination, attentiveness to both positive and negative inner feelings, and independence of judgment (Costa \& McCrae, 1992). It is associated with cognitive abilities tapping dorsolateral PFC functioning (DeYoung, Peterson, \& Higgins, 2005) and is also significantly correlated with self-reported mindfulness (Baer, Smith, \& Allen, 2004). Interestingly, both trait mindfulness (Creswell, Way, Eisenberger, \& Lieberman, 2007) and the practice of meditation by skilled practitioners (Holzel et al., 2007) are associated with activation of PFC in functional magnetic resonance imaging studies.

The above research demonstrates that there are several factors that affect the development of age.-related cognitive decline and that stress can exacerbate this process. Fortunately, if an individual has experienced prolonged exposure to stress, the changes that result are somewhat reversible (Luine, Villegas, Martinez, \& McEwen, 1994). In a longitudinal study, Seeman and colleagues (1997) showed that although 
high cortisol levels were associated with poor memory performance at baseline, women who evidenced decreasing cortisol over 4 years displayed improvements in memory performance. Given that age-related cognitive decline and stress both involve similar neurochemicals and brain structures, research focused on reducing stress levels and improving cognition in an expanding aging population is imperative. One intervention, called mindfulness.-based stress reduction (MBSR), originally developed by Jon Kabat-Zinn (1990), may ameliorate this risk factor.

\section{Mindfulness as a Potential Intervention for Cognitive Decline}

Similar to the personality factor of Openness, mindfulness is defined as "moment--to-" moment awareness" (Kabat-Zinn, 1990, p. 2). It is cultivated by purposefully becoming aware of one's thoughts and feelings in the present moment without judgment. MBSR is a program based on accepting thoughts, feelings, and behaviours that are difficult or impossible to change and encouraging metacognitive processes that emphasize experience of the present moment (Kabat-Zinn, 1990). The standard MBSR program is an 8-week program that teaches participants to suppress the habitual tendency to automatically engage in, and respond to, evaluative and negative mental states (Kabat-Zinn, 1990). Participants are encouraged to become aware of their emotions, cognitions, and behaviours with an interested, accepting and nonjudgmental attitude (Segal, Williams, \& Teasdale, 2002). Eventually, this practice is believed to not only lead to change in actual thoughts and behaviours, but also in the attitudes toward those thoughts and behaviours (Kabat-Zinn, 1990). The cognitive mechanisms involved in mindfulness are hypothesized to be sustained attention (to maintain awareness of current experience), attention switching (to bring attention back to the present moment when it wanders), attentional inhibition (to avoid 
cognitive rumination) and non-directed attention (to enhance awareness of present experience, without assumptions or expectations; Bishop et al., 2004).

The efficacy of MBSR as a cost-effective stress management technique has been evaluated for over two decades in a variety of populations, including patients with chronic pain (Kabat-Zinn, 1982), medical/premedical school students (Shapiro et al., 1998), and cancer outpatients (Carlson et al., 2003; Speca et al., 2000). Overall, these studies have shown MBSR to be efficacious in improving psychological wellbeing and various stress--related health outcomes (Kabat-Zinn, 1990). Specifically, beneficial effects have been reported for symptoms of general distress (Astin, 1997; Carlson, Speca, Patel, \& Goodey, 2003; Speca, Carlson, Goodey, \& Angen, 2000), worry, rumination, and anxiety (Jain et al., 2007; Kabat-Zinn et al., 1992), depressive symptoms (Astin, 1997; Shapiro, Schwartz, \& Bonner, 1998; Speca et al., 2000), and quality of life (Brown \& Ryan, 2003; Carlson et al., 2003). Grossman, Niemann, Schmidt, and Walach (2004) conducted a meta-analysis of randomized controlled trials examining the relationship between MBSR and health outcomes. They calculated the mean effect size for the difference between mindfulness meditation and various control groups on a variety of mental health variables and found a mediumsized ( $d=0.54)$ effect, suggesting that mindfulness training might enhance the ability to cope with general distress. Notably, none of these studies were conducted on a sample consisting exclusively of older adults; a review of mindfulness-based interventions reported the mean age for 18 studies ranged from 38-51 years (Baer, 2003).

Although only a handful of studies have examined the benefits of MBSR in older adults, they have yielded promising results. Findings indicate that MBSR 
training in older adults can improve emotional wellbeing by reducing loneliness, general emotional distress, and symptoms of depression and anxiety (Young \& Baime, 2010). MBSR has also been found to improve physical health parameters, including reduced blood pressure (Palta et al., 2012), reduced pain (Morone, Lynch, Greco, Tindle, \& Weiner, 2008), and improved immune functioning (Moynihan et al., 2010), all of which have a link to the stress response.

Although the above studies have largely relied on self-report measures of outcomes, MBSR has also been found to impact objective measures of stress. For instance, Carlson, Speca, Faris, and Patel (2007) assessed salivary cortisol three times per day at pre-"- and post--MBSR intervention and again at 6- and 12-month follow.-up in a sample of middle-aged cancer patients. The authors found that all morning, afternoon, evening, and mean cortisol levels decreased from pre- to post-intervention, and decreased linearly across the year of follow-up. The authors also found significant improvements in overall perceived stress and quality of life (Carlson et al., 2007). Thus, it is postulated that MBSR decreases stress-related disorders, such as depression, by normalizing HPA function (for a meta-analysis, refer to Matousek, Dobkin, \& Pruessner, 2010). In a similar vein, given the connection between stress and cognitive function, MBSR may be an effective strategy to enhance or maintain cognitive function.

The reported results of MBSR on cognitive functioning have been promising. Jha, Krompinger, and Baime (2007) examined attentional performance before and after either an 8--week MBSR course administered to meditation-naïve participants, a 1-month intensive mindfulness retreat administered to participants with previous meditation experience, or an 8-week no treatment control group. They concluded that 
meditation training (either additional or newly learned) improves voluntary top-" down attentional control as measured by the Attention Network Test (Fan, McCandliss, Sommer, Raz, \& Posner, 2002). Wenk-Sormaz (2005) examined the effects of brief mindfulness training on performance on the Stroop task (Stroop, 1935), a measure of executive function, using healthy young meditation-naïve participants. Relative to the attentional control conditions, three 20-minute sessions of mindfulness meditation was associated with less Stroop interference and more flexible word production, suggesting that even brief exposure to mindfulness practice can improve attentional control.

In another study by Jha, Stanley, Kiyonaga, Wong, and Gelfand (2010), the effects of an MBSR program on working memory ability was explored in two military cohorts as they went through a predeployment process, which is documented to be an extremely stressful and highly demanding interval of time (Bolton, Litz, Britt, Adler, \& Roemer, 2001). When compared with a civilian control group, the military personnel who did not receive mindfulness training experienced a degradation of working memory. Among the military personnel who were given mindfulness training, not only did they see memory improvement when compared with the cohort who did not receive training, but they also saw an increase in working memory capacity with increased mindfulness practice time (Jha et al., 2010).

Lykins, Baer, and Gottlob (2012) similarly found that adults with long-term mindfulness meditation practice (average duration of 6 years) were significantly better than matched nonmeditators on tasks measuring short-term memory (both free and cued recall) and long-term memory (free recall only). Interestingly, there were no group differences on measures of sustained attention, attentional switching, 
inhibition, or working memory, suggesting that the cognitive outcomes of mindfulness warrant further clarification. Anderson, Lau, Segal, and Bishop (2007) found similar negative results, concluding that an 8-week MBSR course for healthy adults resulted in no differences in sustained attention, attentional switching, inhibition, or nondirected attention when compared with a waitlist control group.

More recently, Lenze at colleagues (2014) examined the effects of MBSR on cognitive function using a sample of 34 older adults with clinically significant anxietyrelated distress and co-occurring cognitive dysfunction. Participants were assigned to either a traditional 8-session MBSR group or a modified 12-session MBSR group, and were asked to complete a cognitive battery pre- and post-intervention. Participants showed statistically significant improvements on measures of immediate and delayed recall and executive function, regardless of which group they participated in.

Furthermore, the authors found that the intervention reduced worry severity and that participants were highly satisfied with the intervention. Moynihan and colleagues (2013) found that compared with a waitlist control group, MBSR was able to produce small but significant changes in executive functioning in a sample of healthy older adults.

The MBSR literature contains several gaps, in part resulting from a failure to adhere to a standard intervention protocol. As reviewed previously, some researchers reported findings from studies comparing long-term mindfulness meditation practitioners with meditation-naïve participants (Lykins, Baer, and Gottlob, 2012), while others used brief 20-minute practices (Wenk-'Sormaz, 2005), and others made major alterations to the standard protocol (Jha, Stanley, Kiyonaga, Wong, and Gelfand, 2010). This lack of standardization makes it difficult, if not impossible, to compare 
findings across studies and determine the utility of an MBSR program through replication. It is thus imperative that the standard Kabat--Zinn (1990) protocol is followed across studies to establish a foundation for its utility before major modifications are made, as it is a secular program developed out of Buddhist traditions, and is currently the most widespread manualized protocol available.

Another limitation of the literature is that studies have failed to incorporate a control group or have used waitlist control groups rather than active control groups. Although waitlist control groups are useful as a group comparison, active control groups have several benefits. For instance, they allow researchers to draw conclusions about whether the experimental intervention is efficacious over and above the effects of participation in a research group and its related non-specific factors. In the current study, the active control group controlled for the effects of contact with a researcher, duration of weekly sessions, social engagement within a group setting, cognitive stimulation, and completing at-home assignments.

Despite these limitations, in a review of 23 controlled, case-control, or randomized controlled studies examining the effect of mindfulness--based training on cognitive functioning among participants ranging in age from 18-75 years old, Chiesa, Calati, and Serretti (2011) concluded that mindfulness-based practices "could provide significant benefits on several measures of cognition" (p. 462). The authors noted that executive function in particular deserves further investigation given that the substantial psychological benefits following mindfulness training are thought to depend, at least partly, on executive function (Baer, 2003). These authors suggest that high quality studies using standardized mindfulness programs are needed in order to address the aforementioned discrepancies in the literature. Thus, the goal of the 
current study is to determine whether a standard MBSR protocol can improve cognitive and psychological functioning in a sample of healthy older adults, compared with an active control group.

\section{Objectives and Hypotheses}

Given the documented robust association between perceived stress and cognitive declines with aging, the current proposed pilot study aims to assess the effects of a standardized MBSR program on cognitive function in healthy older adults.

Furthermore, the current study aims to replicate previous findings on psychological wellbeing.

Specifically, the objectives and hypotheses are:

1. To determine whether MBSR can improve executive functioning in a sample of healthy older adults.

- Hypothesis: Compared with the control group, MBSR will be associated with a significant improvement in executive functioning.

2. To examine the effects of MBSR on a number of psychosocial outcomes.

- Hypothesis: Compared with the control group, MBSR will be associated with significantly improved mindfulness, mood, self-esteem, self-efficacy, quality of life, and perceived stress.

The current study was designed as a pilot study and as such, also aims to assess the acceptability of the interventions, assess recruitment potential and retention rates, and determine process time. Overall, this study was conducted to assess the feasibility of a larger, full-scale study. 


\section{Method}

\section{Participants}

Two hundred forty-four individuals were contacted and 169 individuals were excluded at the point of screening. The most common reason for exclusion from the study was being unable to make the time commitment, followed by not meeting inclusion criteria (described below), and lastly, declining to participate upon hearing the study details. The 75 remaining participants were randomly assigned to either the MBSR or control condition. One potential participant completed the baseline cognitive testing session, but withdrew her consent once she learned of the group to which she had been randomized. This participant's baseline data are included in the ITT analyses. Figure 1 contains a CONSORT chart of participant flow from initial recruitment, pre-test, randomization, treatment completion, follow-up testing, and analysis.

\section{Procedure}

Participants were recruited through a combination of online recruitment advertisements, educational community talks/events, and through the Ryerson Senior Participant Pool, which is a Ryerson University-maintained database of older adult participants. Eligible individuals were required to be at least 63 years of age and living independently in the community. Furthermore, they were required to have learned English by the age of 6 years, be able to hear normally, and be able to attend 8 weekly sessions on the Ryerson campus. Participants were excluded if they endorsed any medical or psychiatric conditions that might significantly affect cognitive

performance, such as a neurodegenerative disorder, recently diagnosed psychopathology, cancer, stroke, transient ischemic attack, and diabetes. Participants 
who endorsed regular, active participation in any mindfulness-based activities such as yoga, meditation, or tai chi were also excluded. Further, individuals were excluded if they had undergone neuropsychological testing in the past year (using a similar cognitive battery) due to potential learning effects.

Individuals who responded to the study recruitment strategies (i.e., online and print advertisements) were provided with details of the study purpose and procedure during a telephone call (see Appendix A). Interested individuals were asked a series of questions to assess and confirm study eligibility (see Appendix B). Ineligible participants were thanked for their time and received no monetary compensation. Eligible participants were asked to undergo a 1-hour pre--intervention testing session 1 to 2 weeks prior to commencement of the randomized intervention. During the initial testing session, the researcher completed informed consent procedures, after which both parties signed the form (see Appendix C). Following consent, participants were administered a battery of cognitive tests and further completed a packet of psychological questionnaires.

After the battery was complete, the participants were told whether they were randomly assigned to MBSR or the reading and relaxation (R\&R) control group. After the 8-week intervention phase, all participants were asked to complete a post-.intervention testing session in which a comparable battery of cognitive tests was administered. For the purposes of the current study, which focused on immediate effects of an 8-week program on cognitive function, no long-term follow-up data are presented. However, it is recognized that long-term follow-up is important for determining the efficacy of the intervention and thus participants were invited for a 3month post-assessment session to measure the long-term effects of the interventions 
as part of the parent study. This protocol was approved by the Ryerson University

Research Ethics Board (2012-192).

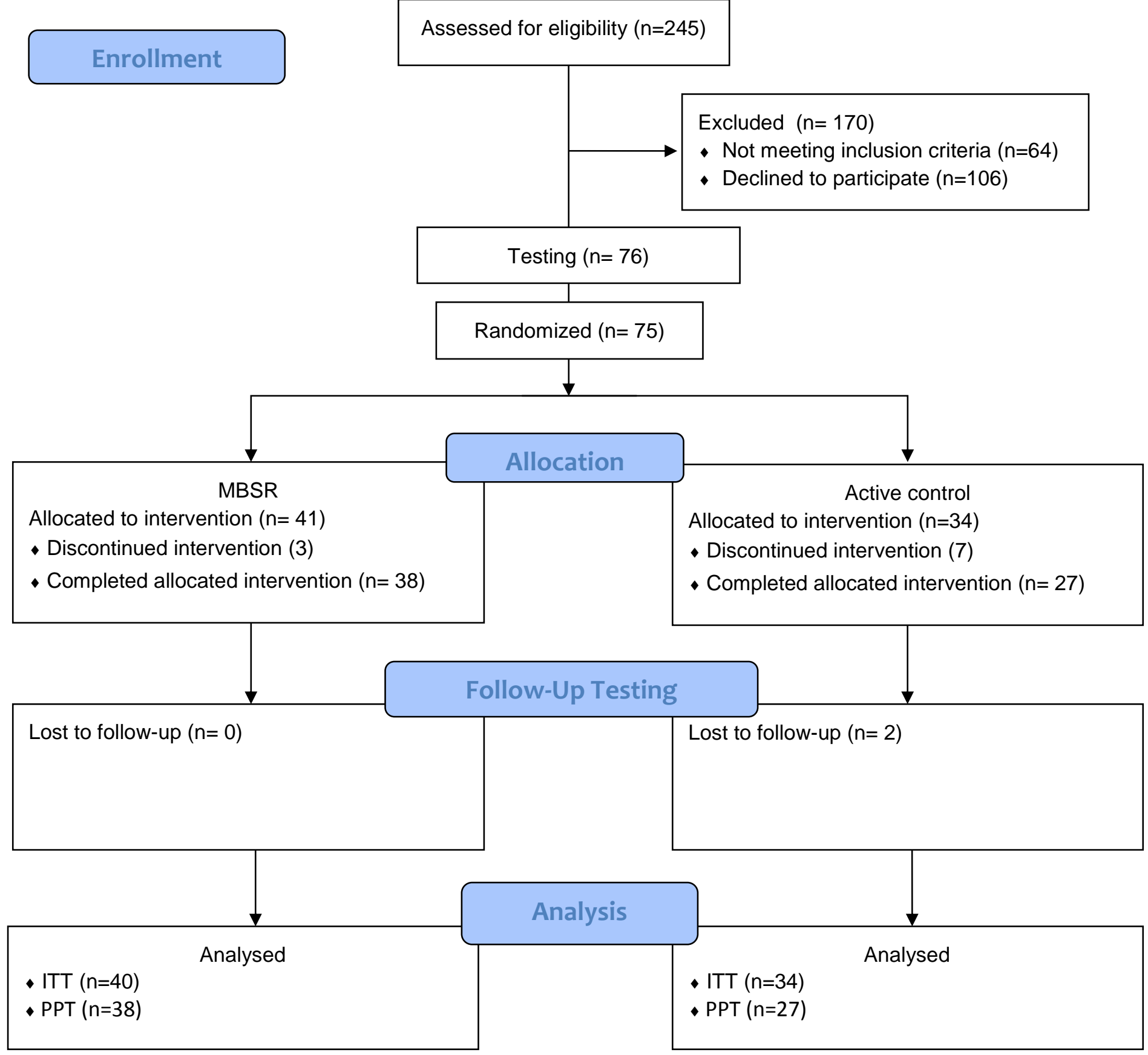

Figure 1. CONSORT diagram showing participant flow and distribution

\section{Interventions}

The first cycle of group sessions began when a total of 30 people were deemed 
eligible to participate and were randomly and evenly assigned to one of the two conditions:

Mindfulness-based stress reduction (MBSR). The MBSR intervention consisted of eight weekly group sessions lasting 2.5 hours each. MBSR was administered according to the standardized protocol created by Kabat-Zinn (1990; see Appendix D for full description), with three minor modifications made to cater to the older adult population (i.e., replacing the "Mindfulness in the Workplace" module with a "Mindfulness for Interpersonal Relationships" module since most of the participants were not actively employed, shortening daily practice time from 45 to 30 minutes to avoid physical discomfort associated with sitting for long periods of time, and eliminating the full-day retreat due to logistical issues). Kabat-Zinn encourages the program to be modified slightly to meet the needs of the specific group of participants (1990), so we are confident that these minor alterations did not affect the fidelity of the program.

Participants were taught various meditation practices that were applied in the course and also assigned to be routine daily activities. Participants engaged in body scans, sitting meditations, and light hatha yoga (see Appendix D). Participants were required to complete $30-45$ minutes of homework per day, which consisted of practicing the techniques learned in each week's class. The MBSR groups were led by trained MBSR practitioners Robyn Hurlow, B.A. (Hons) and Kathryn Curtis, M.A., Kirstin Bindseil, M.S.W., R.S.W., and Alexandra J. Fiocco, Ph.D. Each of these individuals has experience facilitating MBSR groups and working with older adults.

Reading \& relaxation (R\&R). The R\&R control group was made up of two components: (a) a reading component and (b) a relaxation component (i.e., 
progressive muscle relaxation; PMR) and was designed to control for the nonspecific aspects of the MBSR program. As with the MBSR group, the R\&R group met once per week for 2.5 hours over 8 weeks at the same time of day. In the first half of each weekly session, the researcher led participants in a discussion about their thoughts on the story, similar to a book club (see Appendix E for stories). The PMR component of the group took place in the second-half of each weekly session and followed a modified protocol established by Bernstein, Borkovec, and Hazlett-Stevens (2000; see Appendix E for full description). The reading component of the group controlled for cognitive and social engagement and the PMR component controlled for the meditation aspects of MBSR. To control for the time spent completing homework, participants were required to read a short story and engage in 30-45 minutes of daily PMR exercises each week. The R\&R group was led by Sasha Mallya, B. A. (Hons.), who has experience conducting research with older adults and using PMR in clinical settings.

Although controlling for the effects of group facilitator across the MBSR groups and between MBSR and R\&R was not possible, a facilitator feedback questionnaire was administered to participants at the end of the intervention to measure whether the facilitators were comparable on a variety of non--specific therapist characteristics (see Appendix F for further detail). Participants in both groups received audio compact discs to facilitate their at-home mindfulness or PMR practice, and were asked to log their daily practices. Facilitators in both groups completed an intervention fidelity checklist at the end of each session to ensure self.adherence to the protocol (see Appendix G). In total, three cycles of each intervention were offered. Participants who either dropped out of the intervention or declined to 
complete the cognitive assessment were contacted in order to document their reason(s) for discontinuing their participation in the project. All participants' data were analyzed, even if they dropped out (see Data Analysis for further detail).

\section{Measures}

Participants completed a cognitive battery and a set of self-report questionnaires within 1 to 2 weeks before (pre-testing) and after (post-testing) the intervention. These measures consisted of cognitive and self-report measures of wellbeing.

\section{Cognitive measures.}

Global cognitive function. The Mini-Mental State Examination (MMSE; Folstein, Folstein, \& McHugh, 1975) is a brief cognitive screening tool of global cognitive function rated on a 30-point scale. It consists of 11 items representing several cognitive domains, including orientation to time and place, verbal memory, attention, language comprehension and production, and visual construction. Scores of 27 and above are associated with normal cognitive function. The MMSE has been judged to have satisfactory sensitivity and construct validity to cognitive impairment (Tombaugh \& McIntyre, 1992) and is sensitive to change (Roselli et al., 2009).

Executive function. Trail Making Tests A \& B (TMT; Reitan \& Wolfson, 1993) were used to evaluate information processing speed, visual scanning ability, integration of visual and motor functions, mental flexibility, and set shifting. TMT-A requires participants to connect 25 consecutively numbered circles using straight lines. TMT-B requires subjects to connect consecutive numbers and letters, alternating between the two sequences (i.e., 1-A-2-B-3-C). TMT-B is a timed task, and faster time-to-complete is associated with better functioning. It is sensitive to age- 
related decline in executive functioning (Rasmusson, Zonderman, Kawas, \& Resnick, 1998). Calculating the proportional score (TMT B-A/A) provides a sensitive index of prefrontal cortex functioning (Stuss et al., 2001). Previous research indicates that TMT scores are sensitive to change after an MBSR intervention (Johansson, Bjur, \& Rönnbäck, 2012).

The Controlled Oral Word Association Task (COWAT; Eslinger, Damasio \& Benton, 1984) was used to measure verbal fluency, another PFC-dependent ability. It has been found to be a sensitive indicator of executive dysfunction. The COWAT consists of three word-naming trials and participants are asked to verbally generate as many words as they can think of when prompted with a letter of the alphabet (F, A, and S) and a category (Animals). This task not only requires participants to demonstrate semantic knowledge using phonological or categorical rules, but it also requires them to use executive functions to track prior responses and block intrusions (i.e., words that don't fit the rule; Kemper \& McDowd, 2008). This measure is sensitive to age-related decline in verbal fluency (Steinberg, Bieliauskas, Smith, \& Ivnik, 2005) and has been used previously with older adults (Anderson-Hanley et al., 2012).

An alternate version of the TMT was administered and counterbalanced to minimize learning effects. The alternate version of the TMT is comparable to the original version; Franzen, Paul, and Iverson (1996) found no significant differences in overall level of performance between TMT Part A and its alternate form, and between TMT Part B and its alternate form, in a sample of closed head injury patients. These authors found reliability estimates of $r=.70$ for TMT A and its alternate form, and $r=$ .78 for TMT B and its alternate form. Their results indicate adequate reliability of the alternate forms for TMT. However, the alternate version of the COWAT was not used, 
as previous research indicates a difference in difficulty between the alternate and original forms (Barry, Bates, \& Labouvie, 2008).

\section{Psychosocial Questionnaires (see Appendix F).}

Mindfulness. The Mindful Attention Awareness Scale (MAAS; Brown \& Ryan, 2003) was used as a dispositional measure of mindfulness. It is a 15-item scale that measures the frequency of mindful states in day.-to-"day life in both general and situation--specific statements. Higher scores are indicative of greater mindfulness. It has been used previously to measure mindfulness in older adults and has a Cronbach's alpha level of 0.87 among the general adult population in the United States (Morone, Rollman, Moore, Qin, \& Weiner, 2009). It has demonstrated sensitivity to change after an MBSR intervention (Shapiro, Brown, \& Biegel, 2007).

Perceived stress. The Perceived Stress Scale (PSS; Cohen, Kamarch, \& Mermelstein, 1983) measures the degree to which situations in one's life are appraised as stressful. The scale includes items designed to measure how often individuals find their lives unpredictable, uncontrollable, and overloaded during the last month. Internal consistency is good $(\alpha=.85)$, and the stability of the test-retest coefficients ranges from .75 to .86 (Cohen, Kamarch, \& Mermelstein, 1983). This scale has been used among older adult populations (Hamarat et al., 2001) and has been shown to be sensitive to change with a MBSR intervention (Shapiro et al., 2007).

Depression. The Geriatric Depression Scale (GDS; Yesavage et al., 1983) was used to measure depression in the elderly. It is a 30-item scale with clinical cutoff points at $5 \pm 4$ (Normal), $15 \pm 6$ (Mildly depressed), and $23 \pm 5$ (Very depressed). It has demonstrated good capacity for discriminating between depressed and nondepressed elderly people (Montorio \& Izal, 1996) and additionally shows sensitivity 
to change following a psychological intervention (Thompson, Gallagher, \& Breckenridge, 1987).

Quality of life. The Quality of Life Scale (QOLS; Flanagan, 1978) measures satisfaction with needs met. It contains 16 items representing 6 domains of quality of life: physical and material wellbeing, relationships with other people, social and civic activities, personal development, and independence. Cronbach's alpha coefficient has been documented at .87 for the general adult population (Burckhardt, Woods, Schultz, \& Ziebarth, 1989). This scale has demonstrated sensitivity to change following an MBSR intervention (Azulay, Smart, Mott, \& Cicerone, 2012).

Self-esteem. The Rosenberg Self-Esteem Scale (RSES; Rosenberg, 1965) is a 10-item measure that assesses global self-esteem. The RSES contains an equal number of positively and negatively worded items and responses are coded on a four--point scale. It is considered to be an appropriate measure of self--esteem in the elderly (Breytspraak \& George, 1979) and a powerful predictor of increased reactivity to stress (Pruessner, Lord, Meaney, \& Lupien, 2004). This scale has previously demonstrated sensitivity to change following an MBSR intervention (Goldin \& Gross, 2010).

Feedback questionnaire. At the end of the follow-up testing session, all participants were asked to complete a feedback questionnaire, consisting of a facilitator component and an intervention component. The facilitator feedback component instructs participants to rate their group's facilitators on a variety of domains in order to allow the researcher to report whether the facilitators of each group were comparable in terms of therapist effects. It is adapted from the Cognitive Processing Therapy: Therapist Adherence and Competence protocol (Wiltsey- 
Stirman, Monson, \& Resick, 2013).

\section{Statistical Analyses}

In determining the sample size needed for this study, a power calculation was conducted using a formula derived from Crawley (2005). The means and standard deviations of the TMT-B were derived from a previous study that examined whether MBSR could improve cognitive performance in older adults (Lenze et al., 2014). Using these findings, the power calculation resulted in an estimate of 122 participants to complete the study in order to make inferences about the population for the primary outcome measure (61 in each group).

The study sample $(N=74)$ consisted of 40 participants in the MBSR condition and 34 in the control condition. It is recognized that the present study was underpowered to detect a significant difference between the groups, but as indicated previously, this pilot study was primarily designed to test a number of important feasibility goals.

Outcome data were assessed for normality and homogeneity of variance and met these assumptions (Field, 2009). One-way analyses of variance (ANOVA) and $\chi^{2}$ analyses were used to analyze between-group differences at baseline. Variables that significantly differed $(p<.05)$ between groups at baseline were considered covariates. A priori variables (education and age) were entered as covariates in all subsequent analyses (Brayne \& Calloway 1990; Deary et al., 2009; Tombaugh, 2004). As sex was not a factor that influences results for either cognitive outcome, it was not considered an a priori covariate (Hester, Kinsella, Ong, \& McGregor, 2005; Tombaugh, Kozak, \& Rees, 1999). In order to test the stated hypotheses, mixed 2x2 ANCOVA was performed, using pre-intervention and post-intervention scores as the within groups 
factor, and group assignment (MBSR, R\&R) as the between groups factor, controlling for age and education.

Data were first analyzed using intention-to-treat (ITT) principles (Fisher et al., 1990). All participants who were randomized into the MBSR and control group were included in analyses regardless of whether or not they completed the intervention. This type of analysis addresses the question of whether the MBSR protocol, if made available to the community, would be superior to the $R \& R$ protocol. From a public health perspective, it would be detrimental to offer MBSR if the majority of participants in this study elected to not complete the protocol, even if those who do complete the treatment find it beneficial (West \& Spring, 2002). Applying the ITT analysis principle provides an unbiased assessment of the efficacy of the interventions and informs community-based decisions about the effectiveness of the MBSR protocol.

Analyses were also conducted on the subsample of participants that attended all sessions (i.e., intervention completers). The 'per protocol treatment' (PPT, or completer) analyses excluded participants who violated the protocol or did not complete the intervention. A completer was defined as someone who attended both cognitive testing sessions and at least six of the eight intervention sessions $(75 \%$ of the intervention). Although the results of PPT analysis usually provide a lower level of evidence for the efficacy of the intervention, from a public health perspective they better reflect the effects of treatment when taken in an optimal manner. This type of analysis can also highlight any unexpected adverse effects of the interventions ("Intention to Treat Analysis," 2012). Analyses were conducted using SPSS version 21.0. All analyses were considered significant at $p<0.05$. 


\section{Results}

\section{Baseline Characteristics of Participants}

Baseline characteristics of the two groups are shown in Table 1. The MBSR and control group did not significantly differ in age, sex, level of education, or any of the cognitive or psychosocial measures. However, there were marginally significant findings, with the MBSR group reporting greater depressive symptomatology and lower quality of life compared with the R\&R group. Although these differences did not reach the a priori significance level of $p<.05$, the cognitive and psychosocial data were analyzed using GDS and QOLS scores as covariates, to assess whether these baseline differences were significantly related to outcome. They were not significantly associated with outcome and thus, were not used as covariates for the subsequent analyses.

Table 1. Baseline characteristics of participants

\begin{tabular}{llll}
\hline Variable & $\begin{array}{l}\text { MBSR }(n=40) \\
\text { Mean (SD) }\end{array}$ & $\begin{array}{l}\text { R\&R }(n=34) \\
\text { Mean (SD) }\end{array}$ & $p$ \\
Age, years & & & \\
Sex, N (\%) & $68.80(4.42)$ & $69.58(4.74)$ & .47 \\
Education, years & $33(82.5 \%)$ female & $22(64.7 \%)$ female & .12 \\
& $15.95(3.83)$ & $16.34(3.35)$ & .65 \\
MMSE & & & \\
TMT-A, time (s) & $28.93(1.61)$ & $28.64(1.25)$ & .39 \\
TMT-B, time (s) & $34.53(10.62)$ & $37.39(14.09)$ & .33 \\
TMT B-A/A & $84.72(28.40)$ & $88.00(44.86)$ & .71 \\
COWAT - FAS, total correct & $2.56(.78)$ & $2.42(1.04)$ & .50 \\
COWAT - Animal, total correct & $47.13(12.04)$ & $43.27(11.28)$ & .17 \\
& $20.65(5.02)$ & $19.21(5.35)$ & .24 \\
MAAS & $4.24(0.73)$ & $4.45(0.73)$ & .33 \\
PSS & $14.08(7.50)$ & $13.41(6.44)$ & .69 \\
GDS & $5.44(4.51)$ & $3.63(3.87)$ & .06 \\
QOLS & $84.84(10.65)$ & $89.81(8.25)$ & .07 \\
RSES & $23.13(5.40)$ & $24.28(4.77)$ & .35 \\
\hline MMSE = Mini-Mental State Examination, TMT = Trail Making Test, COWAT = \\
Controlled Oral Word Association Task, MAAS = Mindful Attention \& Awareness Scale,
\end{tabular}


PSS = Perceived Stress Scale, GDS = Geriatric Depression Scale, QOLS = Quality of Life Scale, RSES = Rosenberg Self-Esteem Scale

Regarding study attrition, 65 participants (86.7\%) completed (i.e., attendance of at least 6 out of 8 sessions) the study. Completion rates for MBSR were $92.7 \%$ and 79.4\% for the R\&R group. Of the 3 people who dropped out of MBSR after beginning the intervention, two participants cited time commitments as their purpose for discontinuing, and one cited unforeseen health concerns. Of the 7 people who discontinued participation in $R \& R$, one person cited unforeseen health problems, two people cited that the time commitment was too great, one expressed discomfort with participating in a group specifically targeted at older adults, one no longer felt comfortable in group settings, and two did not like the PMR component of the group. Although there were more non-completers in the R\&R group, this was not a significant difference, $\chi^{2}(1,72)=2.29, p=.13$. Independent t-tests and $\chi^{2}$ analyses were run to test for differences in demographic factors and dependent variables that may have differentiated completers and non-completers. There were no cognitive or demographic differences, but dropouts reported a significantly lower quality of life, $t(60)=-2.34, p=.02$. Of the 75 individuals randomized into the study, $72(96 \%)$ completed the post-intervention follow-up cognitive testing session.

\section{Cognition}

Controlling for age and education, a 2x2 mixed ANCOVA demonstrated that post-intervention TMT-B performance did not significantly differ as a function of group assignment in either ITT, $F(1,63)=.24, p=.62$, or PPT, $F(1,58)=.00, p=.98$, analyses (see Table 2). 


\begin{tabular}{|c|c|c|c|c|c|c|c|}
\hline & \multicolumn{3}{|c|}{ MBSR } & \multicolumn{3}{|c|}{$\mathrm{R} \& \mathrm{R}$} & \multirow{2}{*}{$\begin{array}{c}\text { Group } \mathrm{x} \text { Time } \\
\text { Interaction } \\
p\end{array}$} \\
\hline & $\begin{array}{l}\text { Baseline } \\
\text { mean (SD) }\end{array}$ & $\begin{array}{c}\text { Post- } \\
\text { intervention } \\
\text { mean (SD) }\end{array}$ & $\begin{array}{c}\text { Mean } \\
\text { Change }\end{array}$ & $\begin{array}{l}\text { Baseline } \\
\text { mean (SD) }\end{array}$ & $\begin{array}{c}\text { Post- } \\
\text { intervention } \\
\text { mean (SD) }\end{array}$ & $\begin{array}{c}\text { Mean } \\
\text { Change }\end{array}$ & \\
\hline ITT, N & 40 & 38 & & 34 & 27 & & \\
\hline TMT-A, seconds & $34.53(10.62)$ & $35.47(12.19)$ & 0.81 & $37.39(14.09)$ & 34.33 (13.69) & -3.06 & .29 \\
\hline TMT-B, seconds & $84.72(28.40)$ & $77.66(31.59)$ & -7.06 & $88.00(44.86)$ & $80.10(31.88)$ & -7.90 & .62 \\
\hline TMT, B-A/A & $2.56(.78)$ & $2.26(0.75)$ & -0.30 & $2.42(1.04)$ & $2.54(1.11)$ & 0.12 & .08 \\
\hline COWAT - FAS, total correct & $47.13(12.04)$ & $45.68(10.15)$ & -1.45 & $43.27(11.28)$ & $45.43(10.99)$ & 2.16 & .29 \\
\hline COWAT - FAS, intrusions & $.89(1.09)$ & $0.97(1.03)$ & 0.08 & $1.10(1.47)$ & $1.32(1.82)$ & 0.22 & .47 \\
\hline COWAT - FAS, repetitions & $1.24(1.52)$ & $1.53(1.62)$ & 0.29 & $2.00(1.75)$ & $1.97(2.40)$ & -0.03 & .46 \\
\hline $\begin{array}{l}\text { COWAT - Animal, total } \\
\text { correct }\end{array}$ & $20.65(5.02)$ & $20.08(5.04)$ & -0.57 & $19.21(5.35)$ & $18.83(4.58)$ & -0.38 & .90 \\
\hline COWAT - Animal, intrusions & 0.00 & 0.00 & 0.00 & 0.00 & 0.00 & 0.00 & -- \\
\hline $\begin{array}{l}\text { COWAT - Animal, } \\
\text { repetitions }\end{array}$ & $0.73(1.35)$ & $0.78(1.34)$ & 0.05 & $0.73(0.74)$ & $0.73(0.98)$ & 0.00 & .94 \\
\hline PPT, N & 36 & 36 & & 27 & 27 & & \\
\hline TMT-A, seconds & $34.81(11.13)$ & $35.36(12.45)$ & 0.55 & $36.07(14.48)$ & $35.22(14.07)$ & -0.85 & .55 \\
\hline TMT-B, seconds & $82.28(28.21)$ & $76.06(31.28)$ & -6.22 & $85.85(46.56)$ & $78.26(32.40)$ & -7.59 & .98 \\
\hline TMT, B-A/A & $2.48(0.73)$ & $2.22(0.70)$ & -0.26 & $2.44(1.07)$ & $2.41(1.10)$ & -0.03 & .29 \\
\hline COWAT - FAS, total correct & $47.08(10.40)$ & $46.25(9.88)$ & -0.83 & $43.56(11.59)$ & $45.56(11.29)$ & 2.00 & .12 \\
\hline COWAT - FAS, intrusions & $0.83(0.97)$ & $0.97(1.03)$ & 0.14 & $1.19(1.55)$ & $1.44(1.89)$ & 0.25 & .59 \\
\hline COWAT - FAS, repetitions & $1.22(1.51)$ & $1.61(1.63)$ & 0.39 & $2.00(1.82)$ & $2.04(2.53)$ & 0.04 & .46 \\
\hline $\begin{array}{l}\text { COWAT - Animal, total } \\
\text { correct }\end{array}$ & $20.94(5.23)$ & $20.11(5.11)$ & -0.83 & $19.93(5.35)$ & $18.93(4.77)$ & -1.00 & .90 \\
\hline COWAT - Animal, intrusions & 0.00 & 0.00 & 0.00 & 0.00 & 0.00 & 0.00 & -- \\
\hline $\begin{array}{l}\text { COWAT - Animal, } \\
\text { repetitions }\end{array}$ & $0.77(1.37)$ & $0.80(1.37)$ & 0.03 & $0.67(.62)$ & $0.70(0.99)$ & 0.03 & .93 \\
\hline
\end{tabular}

ITT = Intention-to-treat, TMT = Trail Making Test, COWAT $=$ Controlled Oral Word Association Task, PPT = Per-protocoltreatment 


\section{Psychosocial Questionnaires}

A series of $2 \times 2$ mixed ANCOVAs were conducted to determine whether there were any group differences in the psychosocial variables over time (see Table 3). Contrary to expectation, the MBSR group endorsed marginally less mindfulness at post-intervention than the R\&R group in PPT analysis, $F(1,58)=3.54, p=.06$ analyses. With regard to quality of life, although there was no significant main effect of time, there was a significant interaction between time and group for both ITT, $F(1,57)$ $=5.12, p=.03$, and PPT, $F(1,53)=4.91, p=.03$ analyses. There were no other group differences.

\section{Verification of Facilitators}

At post-intervention, participants were asked to rate their facilitators on genuineness, warmth, empathy, professionalism, and a number of other non-specific factors (see Appendix F). Analyses indicate that facilitator ratings did not significantly differ between groups, suggesting the absence of non-specific facilitator effects on intervention outcome (all $p s \geq .59$ ).

Since three different MBSR facilitators ran each of the three study waves, ANOVAs were conducted to determine whether facilitator (RK/KH, KB, AJF) was associated with change score on outcome measures. Analyses revealed one

significant difference: AJF's group demonstrated significantly greater improvement on MMSE scores $(M=29.31, S D=.75)$ than $R K / K H ' s$ group $(M=27.86, S D=1.46), F(2$, $35)=4.68, p=.02[-2.73,-.17]$. Although this result is statistically significant, both scores represent normal cognitive functioning. 
Table 3. Psychosocial outcomes, by group and time

\begin{tabular}{|c|c|c|c|c|c|c|c|}
\hline & \multicolumn{3}{|c|}{ MBSR } & \multicolumn{3}{|c|}{$\mathrm{R} \& \mathrm{R}$} & \multirow{2}{*}{$\begin{array}{c}\text { Group } \mathrm{x} \text { Time } \\
\text { Interaction } \\
p\end{array}$} \\
\hline & $\begin{array}{c}\text { Baseline } \\
\text { mean (SD) }\end{array}$ & $\begin{array}{c}\text { Post- } \\
\text { intervention } \\
\text { mean (SD) }\end{array}$ & $\begin{array}{c}\text { Mean } \\
\text { Change }\end{array}$ & $\begin{array}{c}\text { Baseline } \\
\text { mean (SD) }\end{array}$ & $\begin{array}{c}\text { Post- } \\
\text { intervention } \\
\text { mean (SD) }\end{array}$ & $\begin{array}{c}\text { Mean } \\
\text { Change }\end{array}$ & \\
\hline \multicolumn{8}{|l|}{ ITT, N } \\
\hline MAAS & $4.32(0.70)$ & 4.37 (.63) & 0.05 & $4.41(0.73)$ & $4.72(0.88)$ & 0.31 & .09 \\
\hline GDS & $4.44(4.22)$ & 4.22 (3.59) & -0.22 & $2.97(2.72)$ & $3.10(3.74)$ & 0.13 & .67 \\
\hline PSS & $12.00(5.86)$ & $10.28(5.04)$ & -1.72 & $12.14(5.35)$ & $11.61(5.80)$ & -0.53 & .45 \\
\hline RSES & 24.51 (3.87) & $24.80(4.14)$ & 0.29 & $24.67(4.25)$ & $25.37(4.37)$ & 0.70 & .52 \\
\hline QOLS & $88.22(12.21)$ & 89.56 (11.99) & 1.34 & $90.79(7.21)$ & $88.00(7.39)$ & -2.79 & $.03^{*}$ \\
\hline \multicolumn{8}{|l|}{ PPT, N } \\
\hline MAAS & $4.38(0.67)$ & $4.39(0.64)$ & 0.01 & $4.48(0.72)$ & $4.79(0.89)$ & 0.31 & .07 \\
\hline GDS & $4.39(4.28)$ & $4.06(3.54)$ & -0.33 & 3.15 (2.73) & $2.85(3.43)$ & -0.30 & .99 \\
\hline PSS & $11.83(5.99)$ & $10.10(5.05)$ & -1.73 & $11.85(5.41)$ & $11.46(5.71)$ & -0.39 & .39 \\
\hline RSES & 24.55 (3.78) & $24.76(4.22)$ & 0.21 & $25.13(3.78)$ & $26.00(3.74)$ & 0.87 & .40 \\
\hline QOLS & $88.37(11.58)$ & $89.80(11.42)$ & 1.43 & $91.44(6.78)$ & $88.67(7.22)$ & -2.77 & $.03^{*}$ \\
\hline
\end{tabular}

ITT = Intention-to-treat, TMT $=$ Trail Making Test, COWAT $=$ Controlled Oral Word Association Task, PPT $=$ Per-protocoltreatment, ${ }^{*} p<.05$ 


\section{Discussion}

To our knowledge, this is the first study to evaluate the effects of mindfulness training on executive function and psychosocial factors in healthy non-demented older adults in a randomized control study comprised of a standard MBSR protocol and an active control group. Although the study hypotheses regarding cognitive functioning were not supported, the hypothesis that participants in the MBSR group would report greater quality of life than participants in the control group was supported. However, participants in the MBSR group reported marginally less mindfulness than the control group at post-treatment. A number of explanations may clarify the current results. This study also provides greater insight into feasibility and acceptability of mindfulness training in healthy older adults.

Results of the current study are at odds with studies that demonstrate beneficial cognitive effects of MBSR in clinical populations. For instance, Lenze and colleagues (2014) collected data from 34 older adults who endorsed anxiety disorders and/or depression, plus cognitive dysfunction. The participants were randomized into either an 8-week or modified 12-week MBSR protocol. Lenze and colleagues measured patient satisfaction with the protocols, as well as performance on two tasks of executive functioning. At the end of the program, participants noted that the protocol-recommended time to practice yoga was too strenuous, as was the full-day retreat. Regarding cognitive outcomes, both the 8-session and 12-session groups resulted in equal and significant improvements in both measures of executive function. Despite the comparable small sample size, Lenze and colleagues were able to demonstrate a significant improvement in executive function following 8 weeks of MBSR. This finding, in addition to evidence in young adults, highlights the importance 
of considering the targeted population for mindfulness training; namely, individuals reporting high levels of stress and complaints of cognitive problems.

In contrast to Lenze and colleagues' (2014) sample, the present sample was higher functioning; they reported that they engaged in physical activity, were active members of the community, reported low levels of perceived stress, and had a body mass index in the normal range. All of these factors are known to support cognitive health (Yaffe et al., 2009). Indeed, according to normative data, participants in this study performed within the normal range on the TMT-B task for their age and level of education (Tombaugh, 2004). The current sample also scored in the normal range for depressive symptomatology and self-esteem.

As such, the present study may be best conceptualized as a prevention trial. A prevention trial evaluates the efficacy of an intervention aimed to prevent the onset of a condition, in turn prolonging the health and wellbeing of the population in question (Leresche \& von Korf, 2003). In the context of the present study, MBSR was used as a strategy to help healthy older adults maintain their level of functioning. Although it is common for small prevention trials to find no significant differences in outcome measures (e.g., Wesson et al., 2013; Wilksch, 2013), the present study demonstrated that MBSR is associated with improved quality of life compared with an active control group, and additionally, that the control group is somewhat associated with improved mindfulness. Further, the study also provided important information about the feasibility of a more substantial randomized-controlled trial.

One of the major methodological limitations in previous studies is the absence of an active control comparison condition. As previously noted, the inclusion of an active control group helps the researcher control for the effects of contact with a 
researcher, duration of weekly sessions, social engagement within a group setting, cognitive stimulation, and completing at-home assignments. In the current study, participants were randomized to the MBSR condition or a reading and relaxation condition. The control condition was carefully designed to control for the acquisition of relaxation techniques and cognitive engagement.

Interestingly, the control group demonstrated marginally more mindfulness than the MBSR group. Participants in the control group were required to read an engaging short story each week and discuss it at each group meeting. These discussions were consistently lively and well-received. It is possible that by hearing others' opinions each week in a welcoming and supportive environment, the participants cultivated 'openness to experience', which is related to active imagination, attentiveness to both positive and negative inner feelings, and independence of judgment (Costa \& McCrae, 1992) and is also significantly correlated with self-reported mindfulness (Baer, Smith, \& Allen, 2004). Although the facilitator of the control group made every effort to refrain from describing mindfulness principles, the PMR component of the group may have also inadvertently increased mindfulness skills such as body awareness, decreased self-judgment, and attention-switching because participants focused on tensing and relaxing each muscle group in sequence.

It is also possible that the decision to reduce the assigned amount of meditation practice time and the elimination of the day-long retreat within the MBSR intervention resulted in too little mindfulness training to elicit robust changes in executive functioning in this healthy sample. Although previous research has indicated that, in healthy younger adults, mindfulness meditation can improve cognitive performance within a few sessions (Wenk-Sormaz, 2005), healthy older 
adults may require more time to fully integrate this process into their daily lives. This hypothesis may be particularly true for the present sample, who was already very high-functioning to begin with - they may have needed more time to test out mindfulness principles before having enough justification to use them to replace their current (and largely successful) coping strategies. Although Lenze and colleagues (2014) found that 12-weeks of MBSR was no more effective than 8 weeks of MBSR, their sample consisted of individuals with psychiatric illnesses, which means that they may have had greater motivation for incorporating the mindfulness principles into their daily lives.

Lindberg (2005), in a review of research related to meditation and spirituality in the elderly, noted that, although meditation/relaxation can be successfully taught to older adults, none of the 36 studies reviewed included a quantification of learning rates. In a study by Brown and Ryan (2003), the developers of the MAAS, the authors found that the amount of time currently practicing meditation was not associated with MAAS score, but the amount of years of practice was significantly and positively correlated with score on the MAAS. As a result, the authors speculated that it might take substantially longer than 8 weeks of training to produce significant increases in the MAAS. Indeed, in the Buddhist tradition, from where mindfulness-based meditation originates, meditation is described as a lifelong practice in which mindfulness is fostered over a period of many years (Goldstein, 2002).

PMR, on the other hand, is a technique that is easily learned and within days or weeks, enhances awareness of the body, and increases the ability to relax quickly (Morone \& Greco, 2007). Given the physical nature of PMR, it is also a technique that, if performed incorrectly, can be easily corrected. Based on participants' comments, 
formal PMR practice was easier for the participants to integrate into their busy schedules than formal meditation practice. For example, several participants in the control group stated that it was easy for them to integrate the practice into their daily lives, for instance practicing PMR on public transportation or while sitting at a desk. The MBSR participants appeared to have more difficulty finding time to incorporate the various mindfulness practices to their daily routine. Thus, the fact that the control group appeared to be able to learn their stress-reduction technique more quickly, were better able to incorporate it into their daily lives, and were better equipped to practice the technique properly, may account for the unexpected finding that participants in the control group reported greater mindfulness than the MBSR group. It will be informative to study the 3-month follow-up data in a subsequent study to address the possibility that mindfulness and its benefits will become more evident over time. In sum, it is possible that for healthy older adults, a more accessible group such as the Reading and Relaxation group created for this study, may be more beneficial to improving overall wellbeing.

The primary limitation of the present study was the relatively small sample size. It is possible that the inclusion of additional participants would increase the statistical power needed to detect meaningful differences. The study is also limited by the fact that an additional waitlist control condition was not included, which would have allowed us to also replicate previous research (e.g., Moynihan et al., 2013) that showed that MBSR is at least more beneficial than the passage of time. Inclusion of a waitlist control group would also exclude the possibility that the non-significant findings were a result of regression toward the mean.

Regarding the finding that the groups were not significantly different on 
measures of depression, self-esteem, or perceived stress at post-test, this result may be a product of inappropriate measurement. Each of the scales included in the study contains a time-based qualifier in the instructions (e.g., the PSS requires participants to respond according to their experiences in the past month and the MAAS refers to experiences in general) and as such, the questionnaires may not adequately capture the participant's experience since completing the intervention.

Another important and highly speculated factor is facilitator characteristics. Although all facilitators were equally rated on attribute characteristics of warmth, genuineness, professionalism, etc., closer inspection of the three MBSR waves suggested that the facilitator, regardless of level of training, may have significantly impacted outcome (i.e., a therapist effect). Previous research has demonstrated mixed results about the impact of therapist effects in psychological interventions. Although one meta-analysis of individual psychotherapy found that therapist competence plays little role in determining symptom change (Webb, DeRubeis, \& Barber, 2010), another meta-analysis examining the effects of treatment of pain in primary care concluded that there is a small, but identifiable, therapist effect (Lewis et al., 2010). Interestingly, Lewis and colleagues found that psychosocial-based interventions had the highest therapist effects. In the present study, the results did not appear to be influenced by the facilitators' level of training, experience, or non-specific attributes. Thus, in future, it would be interesting to determine therapist qualities that are most associated with improvement in mindfulness-based interventions specifically.

Despite the aforementioned limitations, this study provides valuable insight into the feasibility, acceptability, and effectiveness of psychosocial interventions for older adults. It is important to note that the completion rate in the MBSR course was 
just over 13\% higher than the control group, which suggests that participants were slightly more satisfied with the group. None of the three individuals who discontinued participation in the MBSR group cited disinterest with the group as their reason for discontinuing. Participants who did stay in the group commented that the group helped to "declutter" the mind, increase physical and mental awareness, increase patience and acceptance, reduce physical pain, and enhance the ability to cope with stressors. However, the majority of participants in the control group also gave similarly positive feedback, stating that the group was associated with an improvement in sleep quality, an increased sense of control over stressors, and increased relaxation.

Overall, while the study hypotheses were not supported, the data appear to suggest that MBSR may improve facets of wellbeing in healthy non-demented older adults. It also points to the possible beneficial effects of a group intervention based on reading and relaxation techniques. This study cohort continues to be followed for a 3month follow-up period. Additional cycles will be conducted to meet the sample size stipulated by power calculations. Given that the population is aging, this study provides preliminary evidence that MBSR may increase quality of life with age. 


\section{Appendix A}

\section{Telephone Script for Recruiting}

E.g, "I would like to volunteer for your research" "I heard about your research and would like to learn more about participating"

\section{Older adult calls in, asking about the study.}

You say:

Absolutely, let me tell you a bit about the study.

You are returning a message that was left by an older adult who called in for the study. You say:

Hello, this is [name] from Ryerson University, returning your call regarding a study we are conducting looking at the effects of a program that promotes healthy aging in older adults. Do you have a few minutes to chat?

\section{General script:}

As you probably already know, many people often experience problems with their memory as they get older. Changes in memory and other cognitive abilities, such as your ability to focus and pay attention, your ability to solve problems, or how quick you can respond to things in your environment, can lead to a decrease in overall quality of life.

We are running a study to see if a program tailored to older adults can improve quality of life and cognitive function - such as memory, attention, and how quickly you can solve certain problems.

As a volunteer, you would be asked to come to Ryerson on 10 occasions. The first session, which will be scheduled in the morning, will last for one hour. During this one- hour session, you will be asked to do a few tasks that assess your cognitive function - such as memory, attention, and problem solving. You will also be asked to fill out a few questionnaires that ask about things like your mood, your self-esteem (or how you feel about yourself), and the amount of stress you experience in your daily life. You will be paid $10 \$$ at the end of the session for your time. You will also be reimbursed $4 \$$ for TTC transit to and from Ryerson.

After the first session, you will begin the program that is held at Ryerson once a week for 8 weeks in a row. Each weekly session will last 2.5 hours will be in a group of about 10 people.

If you decide to participate, you will be randomly assigned to one of two programs. It is important for you to know that you will not be able to choose which program to participate in. 
One of the 2 programs is called Mindfulness-Based Stress Reduction (or MBSR). The other program is a reading/relaxation group. You will be assigned to one of these two programs.

Mindfulness-based Stress Reduction, or MBSR, is a program that was developed in the United States in the 1970s and is now used to decrease stress and increase wellbeing. It combines relaxation, light stretching and meditation (or sitting quietly while concentrating on your breath). Everything that is done in class is tailored to your comfort level (e.g. you will not be pushed to stretch more than you can). There are 8 sessions in total, once a week, each lasting 2.5 hours. A trained MBSR practitioner will lead the group each week. Each week, you will meet with a group of no more than 10 people for 2.5 hours of MBSR and you will also get a bit of homework (approximately 20-30 minutes a day) which will help you practice what you learned during the session in your everyday life.

The reading/relaxation group will consist of two components: A reading component and a relaxation component. Each week, you will be assigned a short story that you will be asked to read at home. In the first half of each weekly session, Dr. Fiocco will lead group members in a discussion about your thoughts on the story, similar to a book club. The second component involves learning muscle relaxation techniques. There are 8 sessions in total, once a week, each lasting 2.5 hours. Dr. Alexandra Fiocco, an Assistant Professor and researcher at Ryerson who specialized in Aging Research, will lead each session. As a participant in the class, you will have an opportunity to practice skills and learn about various topics such as the risk factors of unhealthy aging and prevention strategies. Each week, you will meet with a group of no more than 10 people for 2.5 hours and you will also get a bit of homework (e.g. readings) which will help you practice what you learned during the session in your everyday life.

You will be reimbursed for TTC transit to and from Ryerson for each visit. Before I go on, do you have any questions about the 2 interventions?

...About one week after the final intervention session, you will come back to complete the same kind of tasks and questionnaires you did during the first session. Again, the session will take place in the morning and you will be paid $10 \$$ for this hour-long session, along with TTC reimbursement.

Are you still interested in participating?

If yes: Wonderful, before we move forward, I will have to ask you a few demographic and health-related questions. 
It is important to tell you that all information you give me today is confidential. Any information that identifies who you are (e.g. your name, telephone number) will be removed from the data and will be stored in a separate locked filing cabinet. All data kept on the computer will be password protected and held for 7 years after publication of study results. After that, all data will be properly destroyed. This applied for the information you give me today and for any information you give me during the study.

...[proceed to phone screening questionnaire]

If no: I understand. Thank you very much for your time and have a wonderful day.

\section{Script Following phone screening questionnaire:}

Person meets criteria: Wonderful! You meet the requirements to participate in this study. Again, all information you have given me today, and all information you will provide during the study, is confidential. Any information that identifies who you are (e.g. your name, telephone number) will be removed from the data and will be stored in a separate locked filing cabinet. All data kept on the computer will be password protected and held for 7 years after publication of study results. After that, all data will be properly destroyed.

I will contact you shortly to book your first testing session. If you have any questions in the mean time, please do not hesitate to contact me [provide contact info]

Person does not meet criteria: I am sorry to say that you do no meet the eligibility criteria for this study. For the purpose of this study, we have excluded XX. Often in research, we have exclusion criteria, to make sure that our sample is relatively the same on certain characteristics. I am very grateful for your time and the information you provided today.

Again, all information you have given me today is confidential. The reason why we keep the information you gave me today is very important for research - it gives us a description of who we were able to recruit and who we were not able to recruit from the community. May I have your consent to use this confidential phone-screen data for this purpose? Again, your name will not be attached to the data.

Thank you for your time 


\section{Appendix B}

Phone Screening Questionnaire

Recruitment Contact Sheet (to be stored with consent form)

\begin{tabular}{|l|l|}
\hline First name: & \\
\hline Last name: & \\
\hline $\begin{array}{l}\text { Phone number (best to contact } \\
\text { you): }\end{array}$ & \\
\hline Other numbers: & $\mathrm{Y}-\mathrm{N}$ - \\
\hline Is it okay to leave a message? & $\mathrm{M}:$ \\
\hline Email address: & $\mathrm{W}:$ \\
\hline $\begin{array}{l}\text { Your availability and the best } \\
\text { time(s) to contact you: }\end{array}$ & \\
\hline & \\
\hline Notes: & \\
\hline
\end{tabular}

Assigned participant code: 


\section{Phone Screening Questionnaire}

Researcher: To determine your eligibility for the study, I will now ask you a few questions about demographic health information. This confidential information will be securely stored in our database and is restricted to members of the research team. You do not have to answer any questions that you are uncomfortable with; however, you may be excluded based on the information you choose to withhold.

\section{AVAILABILITY}

Are you available for 8 weekly sessions?

\section{DEMOGRAPHIC QUESTIONS}

\begin{tabular}{|c|c|}
\hline Age: & \\
\hline Sex: & $\mathrm{M}$ \\
\hline Ethnicity (e.g., Caucasian, Hispanic, etc.): & \\
\hline Country of birth: & \\
\hline $\begin{array}{l}\text { Country/countries of descent (i.e., where you } \\
\text { would trace your ancestry to): }\end{array}$ & \\
\hline Languages you speak: & \\
\hline $\begin{array}{l}\text { If English is not your mother tongue, at what } \\
\text { age did you learn to speak English? } \\
\text { (exclude if learned English after age 6) }\end{array}$ & \\
\hline Handedness: & Right __ Left ___ Ambidextrous \\
\hline Do you drive? & $\begin{array}{l}\text { No } \_ \text {Yes } \\
\text { If no, do you have a driver's licence? }\end{array}$ \\
\hline Are you retired? & $\begin{array}{l}\text { No } \_ \text {Yes } \\
\text { If yes, in what year did you retire? }\end{array}$ \\
\hline How many years of education do you have? & \\
\hline Do you practice ... & $\begin{array}{l}\text { Yoga No / Yes } \\
\text { Meditation No / Yes }\end{array}$ \\
\hline
\end{tabular}




\begin{tabular}{|l|l|}
\hline (Exclude if practice >3 times a week) & $\begin{array}{l}\text { Tai Chi No/ Yes } \\
\text { Martial Arts No/Yes } \\
\text { Progressive Muscle Relaxation No /Yes }\end{array}$ \\
\hline $\begin{array}{l}\text { Have you ever received any cognitive or } \\
\text { neuropsychological testing? } \\
\text { (Exclude if within the last year) }\end{array}$ & \\
\hline
\end{tabular}

\section{HEALTH-RELATED QUESTIONS}

\section{Have you ever had any of the following?}

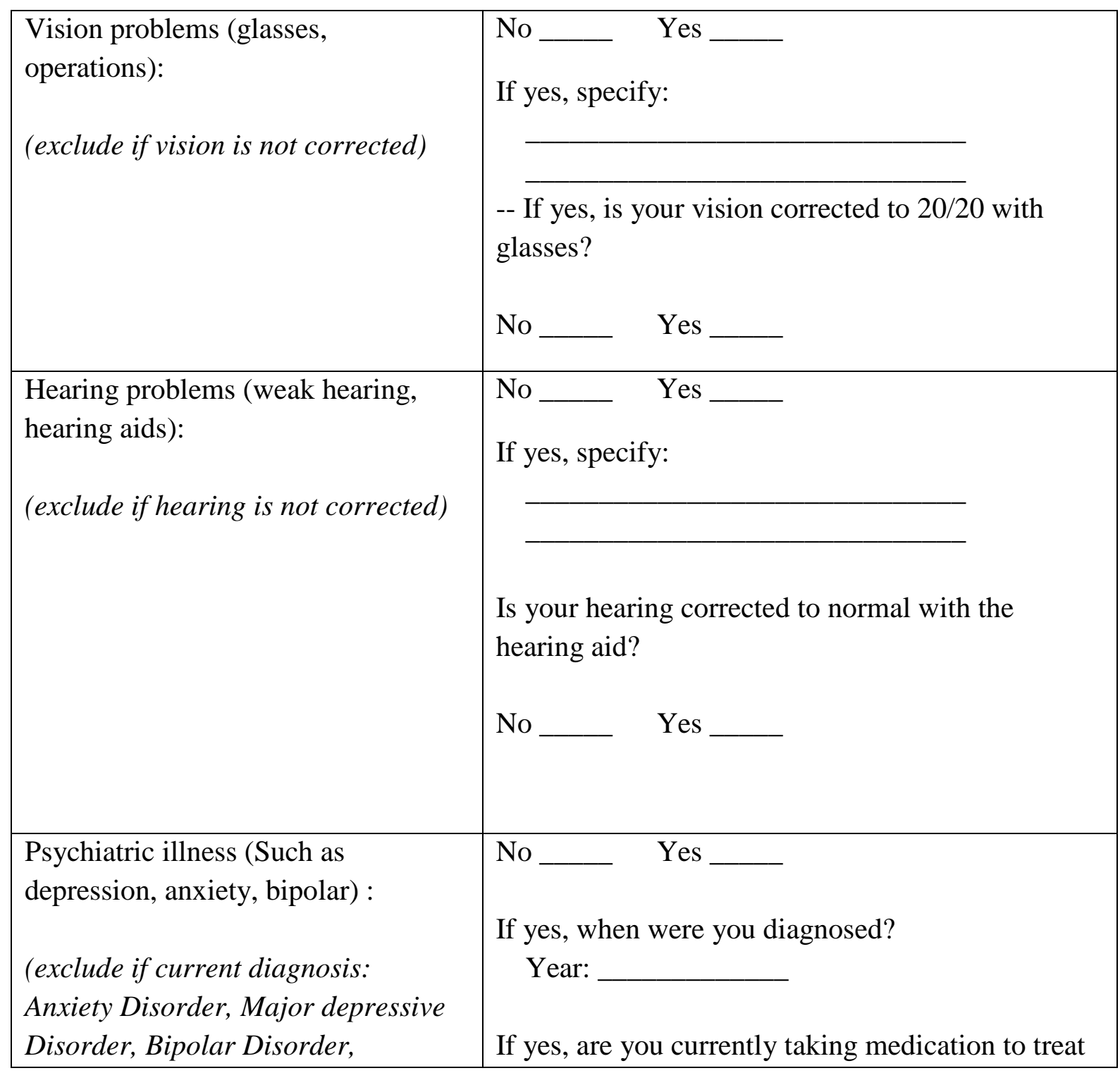




\begin{tabular}{|c|c|}
\hline $\begin{array}{l}\text { Psychotic Disorder (Schizophrenia), } \\
\text { Eating Disorder, Dissociative } \\
\text { Disorder, Personality Disorders) }\end{array}$ & $\begin{array}{l}\text { your symptoms? } \\
\text { No ___ Yes }\end{array}$ \\
\hline $\begin{array}{l}\text { Depression: } \\
\text { (exclude if current) }\end{array}$ & $\begin{array}{l}\text { No _ Yes } \\
\text { If yes, when were you diagnosed? } \\
\text { Year: } \\
\text { If yes, are you currently taking anti-depressants to } \\
\text { treat your symptoms? } \\
\text { No }\end{array}$ \\
\hline Alcohol use: & $\begin{array}{l}\text { No }- \text { Yes } \\
\text { If yes, how frequently? }\end{array}$ \\
\hline $\begin{array}{l}\text { Illegal/recreational drug use: } \\
\text { (exclude if dependence) }\end{array}$ & $\begin{array}{l}\text { No } \_ \text {Yes } \\
\text { If yes, how frequently? }\end{array}$ \\
\hline $\begin{array}{l}\text { Diabetes: } \\
\text { (exclude) }\end{array}$ & $\begin{array}{l}\text { No _- Yes } \\
\text { If yes, when were you diagnosed? } \\
\text { Year: } \\
\text { If yes, is it controlled with medication? } \\
\text { No __ Yes __ yes, which medication? } \\
\text { Name: }\end{array}$ \\
\hline Hypo or Hyperthyroidism: & $\begin{array}{l}\text { No }- \text { Yes } \\
\text { If yes, is it controlled with medication? }\end{array}$ \\
\hline (exclude if not controlled) & No __ Yes ___ Name \\
\hline $\begin{array}{l}\text { Cancer: } \\
\text { (exclude if chemotherapy or } \\
\text { radiation) }\end{array}$ & $\begin{array}{l}\text { No _ } \\
\text { If yes, when were you diagnosed? } \\
\text { Year: } \\
\text { If yes, did you receive chemotherapy or radiation? }\end{array}$ \\
\hline
\end{tabular}




\begin{tabular}{|c|c|}
\hline & No \\
\hline $\begin{array}{l}\text { Stroke: } \\
\text { (exclude) }\end{array}$ & $\mathrm{No}$ \\
\hline $\begin{array}{l}\text { Aneurysm: } \\
\text { (exclude) }\end{array}$ & No \\
\hline $\begin{array}{l}\text { Heart attack: } \\
\text { (exclude) }\end{array}$ & No __ Yes \\
\hline $\begin{array}{l}\text { High blood pressure: } \\
(\mathrm{SBP}>=140 ; \mathrm{DBP}>=90)\end{array}$ & $\begin{array}{l}\text { No __ Yes } \\
\text { If yes, is it controlled with medication? } \\
\text { No___ Yes__ medication name: }\end{array}$ \\
\hline $\begin{array}{l}\text { Learning disability: } \\
\text { (exclude) }\end{array}$ & No __ Yes \\
\hline $\begin{array}{l}\text { Neurological disease: } \\
\text { (exclude if: } \\
\text { Dementia, } \quad \text { Parkinsons, } \quad \text { MS, } \\
\text { Huntingtons, ALS, Stroke, Seizure } \\
\text { Disorder) }\end{array}$ & No __ Yes \\
\hline $\begin{array}{l}\text { Seizure: } \\
\text { (exclude) }\end{array}$ & No __ Yes \\
\hline $\begin{array}{l}\text { Epilepsy: } \\
\text { (exclude) }\end{array}$ & No __ Yes \\
\hline $\begin{array}{l}\text { Head injury: } \\
\text { (probe for seriousness) }\end{array}$ & No __ Yes \\
\hline Serious car accident: & No __ Yes \\
\hline $\begin{array}{l}\text { Concussion: } \\
\text { (exclude if within last year) }\end{array}$ & $\begin{array}{l}\text { No _ Yes } \\
\text { If yes, how many? When was the last one? }\end{array}$ \\
\hline $\begin{array}{l}\text { Have you ever been unconscious? } \\
\text { (exclude if within last year) }\end{array}$ & $\begin{array}{l}\text { No _ Yes } \\
\text { If yes, how long were you unconscious? } \\
\text { Duration: } \\
\text { If yes, what was the cause? } \\
\text { Cause: }\end{array}$ \\
\hline $\begin{array}{l}\text { Have you ever had surgery that } \\
\text { required general anesthesia? } \\
\text { (exclude if within last year) }\end{array}$ & $\begin{array}{l}\text { No }- \text { Yes } \\
\text { If yes, when did you have this procedure? } \\
\text { Year: }\end{array}$ \\
\hline
\end{tabular}




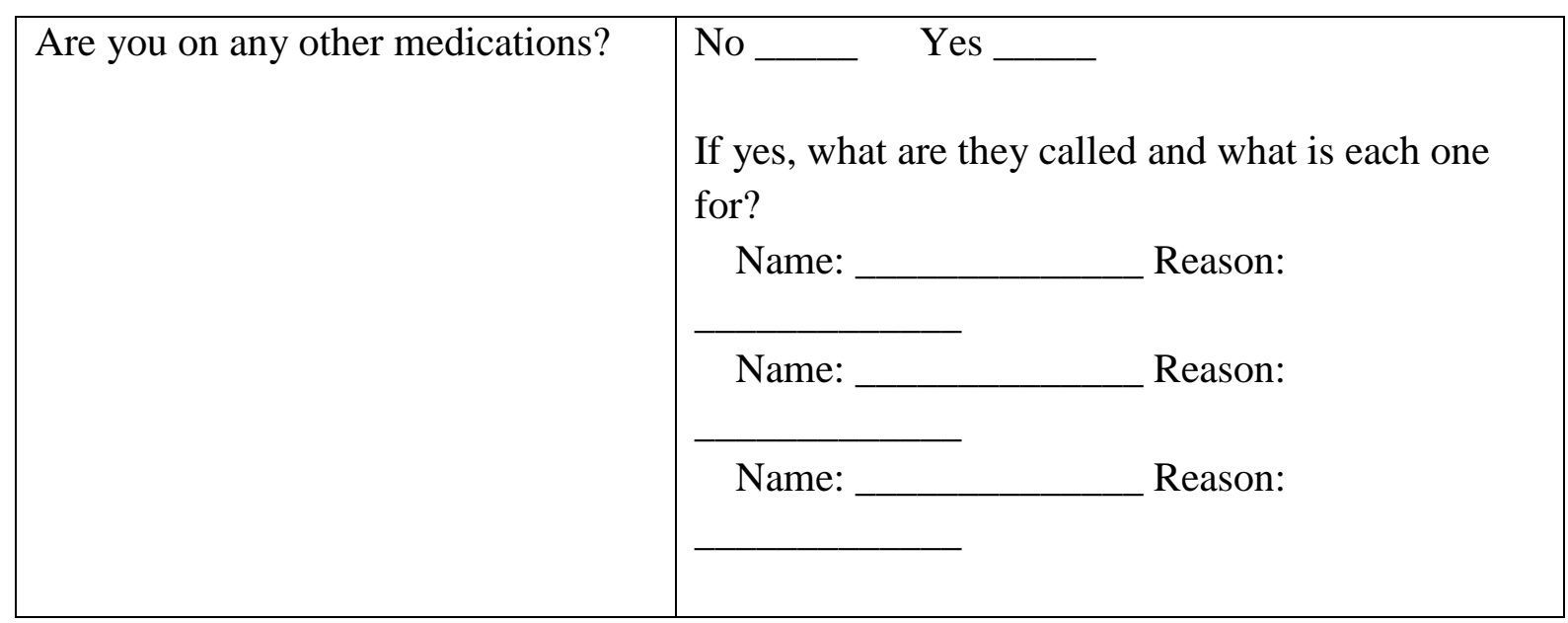




\section{Appendix C}

\section{Ryerson University Consent Agreement}

Study: The Effects of a Program on Cognitive Function and Quality of Life in Older Adults

You are being asked to participate in a research study. Before you give your consent to be a volunteer, it is important that you read the following information and ask as many questions as necessary to be sure you understand what you will be asked to do.

Investigators:

Principal Investigator: Dr. Alexandra J. Fiocco, PhD., Department of Psychology, Ryerson University

Collaborators: Sasha Mallya, BA., Department of Psychology, Ryerson University

Purpose of the Study:

Cognitive function, such as memory, is an important health factor, especially in late life. As our population ages, it is estimated that the number of Canadians with dementia will rise from 250,000 to 592,000 by 2021 . The effect of stress on cognitive function has received a lot of attention over the past 20 years; it is suggested that exposure to high levels of stress hormones over a person's lifespan plays a significant role in the aging process and may contribute to declines in cognitive function, such as memory. With an aging population on the rise, and an expected increase in dementia cases, prevention is key! It is important that prevention programs be developed to prevent or slow the progression of cognitive decline in older adults.

The purpose of this study is to see if an 8-week Mindfulness-based Stress Reduction (MBSR) program or an 8-week Reading \& Relaxation (i.e. progressive muscle relaxation, or PMR) group improves cognitive function (such as memory) and quality of life in older adults. Previous research shows beneficial effects of MBSR and PMR on stress and psychological factors (e.g. depression). Research has also started to evaluate the effects of stress reduction on cognitive function. However, there is very little research (if any) that has assessed the benefits of these programs in healthy older adults.

Forty older adults between the ages of 65 and 80 will be recruited for the study. To be eligible for this study, individuals must be free of the following: recent diagnosed psychopathology or mood disorder, cancer/chemotherapy, neuropsychological testing in past year, stroke, diabetes, significant vision or hearing problems, and nonfluency in English. Participants who meet inclusion criteria will undergo a few tests that assess their memory and other cognitive functions (like speed to do something) and will complete psychological questionnaires before and after the 8-week program. 


\section{Description of the Study:}

Participants will be asked to come to Ryerson University for 10 sessions in total: 2 testing sessions and 8 program sessions.

Two Testing Sessions:

Cognitive testing, such as testing your memory, and questionnaires will be completed in Dr. Fiocco's Stress and Healthy Aging Research Lab at the Institute for Stress and Well Being at Ryerson University. Both sessions will take place in the morning and will last approximately 1 hour. Cognitive tests will include tests that assess overall cognitive function, attention, and memory (30 minutes to complete). Self-report questionnaires will include those that assess mindfulness, perceived stress, depressive symptoms, quality of life, and self-esteem (maximum 30 minutes to complete).

Time commitment for testing sessions:

1 hour in total on each day.

Eight-Week Program:

The Mindfulness Based Stress Reduction (MBSR) program will be led by a trained MBSR practitioner. The 8-week program consists of weekly 2.5-hour-long sessions. In groups of 10-15, participants will be taught various meditation practices that will be applied in class and to routine daily activities. Participants will do relaxation exercises, walking meditation, and light stretching. All activities will be tailored to the comfort of the participant (e.g. stretching). In addition to weekly classes, participants are asked to do 20-30 minutes of homework a day, which includes practicing what you learned in class that week (e.g. daily breathing exercises).

Or

The Reading \& Relaxation group will be divided into two components: a component that is very similar to a book club, and a relaxation component. Each week, the session leader will assign participants to read one short story at home. In the first half of the session, participants will discuss their thoughts about the reading, just like a book club. In the second half of the session, participants will engage in a technique called progressive muscle relaxation (PMR). PMR teaches clients to progressively tense and relax different sets of muscle groups, with the goal of total body relaxation. There are 8 sessions in total, once a week, each lasting 2.5 hours. Each week, you will meet with a group of 10-15 people for 2.5 hours and you will also get a bit of homework (i.e., to read the short story and practice PMR), which will help you practice what you learned during the session. 
Time commitment for the program:

Session: 2.5 hours once a week, over 8 weeks

Homework: 120- 180 minutes a week, over 8 weeks (the amount of time you put into your homework is up to you; naturally the more time the better).

What is Experimental in this Study:

The experimental component of this study is undergoing an 8-week program. By agreeing to participate, you are agreeing to be randomized to either program condition (MBSR or Reading \& Relaxation group). This is to say that you are willing to participate in either intervention.

\section{Risks or Discomforts:}

Your participation in this study may create temporary frustration or fatigue from traveling to and from Ryerson University on 10 occasions (2 testing sessions and 8 program sessions). Some of the cognitive tasks (e.g. memorizing a list of words) may be challenging, causing frustration; however, we emphasize that you are not expected to get everything correct and that we only ask you to try your best. Should you feel uncomfortable during the testing session and while filling out psychological questionnaires, you may take a break before moving on.

Fatigue may be experienced due to the demands that class time has on your ability to maintain your attention or focus for a certain period of time. Breaks will be given during each of the 2.5-hour sessions, allowing participants to stretch their legs and disengage from the course material for a few minutes.

Physical discomfort may be experienced during the MBSR and PMR program. Should sitting positions or movements (e.g. stretching) done during the session feel uncomfortable, the instructor will provide modifications to ease any discomfort felt. The MBSR and PMR program is tailored to your ability.

Finally, should you decide that you are no longer interested in volunteering, you may withdraw from the study at any time.

Benefits of the Study:

By participating in this study, you will learn either MBSR or PMR techniques free of charge (these programs often cost over \$300). Although direct benefits are not guaranteed, your participation in this study will help us realize the impact of these programs on cognitive function and well-being in older adults. With population aging, and a projected increase in dementia cases, it is important to find a prevention strategy that will prevent or slow the progress of cognitive decline.

Confidentiality:

All data collected for this study will remain confidential. Research records will be kept 
in a cabinet file to which only the principal investigator of this study as well as her research assistants will possess the key. Moreover, data will be coded in order to prevent any assistant from making a link between a participant's name and test results, thus maintaining confidentiality of test results. All data will be securely stored up to 7 years following publication of results, after which all material will be properly destroyed.

Incentives to Participate:

The main incentive for participants is to experience a free program tailored to older adults for 8 weeks. In addition, a small incentive of $\$ 20$ will be administered for the two testing days (one before and one after the program is complete). Further, \$4/visit will be given to compensate for traveling to and from Ryerson. Thus, upon completion, participants will be compensated $\$ 60$ in total.

\section{Costs and/or Compensation for Participation:}

There are no costs associated with taking part in this study. All material associated with the intervention will be free of charge. As mentioned above, participants will be compensated $\$ 20$ for undergoing cognitive testing and will also be compensated $\$ 4 /$ visit for cost of transit.

\section{Voluntary Nature of Participation:}

Participation in this study is voluntary. Your choice of whether or not to participate will not influence your future relations with Ryerson University. If you decide to participate, you are free to withdraw your consent and to stop your participation at any time without penalty or loss of benefits to which you are allowed.

At any particular point in the study, you may refuse to answer any particular question or stop participation altogether. If you decide to stop participating, all information that you provided before stopping will remain confidential in a secured database at Ryerson University and used for future analyses. This data will be kept for up to 7 years following publication of results.

What will be done if "abnormal" findings/results are obtained:

The tests that you will complete are not "diagnostic" - i.e. no diagnosis can be made with the tests that we administer you. However, if there is anything about your performance on the tasks and questionnaires that raises a concern for us, we will discuss it with you.

Questions about the Study:

If you have any questions about the research now, please ask. If you have questions later about the research, you may contact the principal investigator: Alexandra J. Fiocco via phone (416-979-5000 ext 3008) or email (afiocco@psych.ryerson.ca).

If you have questions regarding your rights as a human subject and participant in this study, you may contact Dr. Nancy Walton (Chair) or Toni Fletcher (REB Coordinator) 
of the Ryerson University Research Ethics Board for information via phone (416-9795042) or email (rebchair@ryerson.ca). You may also write them at:

Research Ethics Board

c/o Office of the Vice President, Research and Innovation

Ryerson University

350 Victoria Street

Toronto, ON M5B 2K3

\section{Agreement:}

Your signature below indicates that you have read the information in this agreement and have had a chance to ask any questions you have about the study. Your signature also indicates that you agree to be in the study and have been told that you can change your mind and withdraw your consent to participate at any time. You have been given a copy of this agreement.

You have been told that by signing this consent agreement you are not giving up any of your legal rights.

Name of Participant (please print)

Signature of Participant

Date

Signature of Investigator/Study Coordinator Date

Dissemination of Results:

If you agree to participate in the study, are you interested in learning about the results of the study in a final report? If so, please provide your mailing or email address below:

Email

Mailing 


\section{Appendix D}

\section{MBSR Protocol (Kabat-"Zinn, 1990)}

Weeks 1 and 2

Introduce participants to the foundational attitudes of mindfulness and diaphragmatic breathing. Teach them the body scan practice. The body scan is usually done lying down, but depending on what is comfortable for them, participants may sit or stand. Participants are then guided to pay attention to their bodies starting with the toes, moving up through the body, and ending at the head. The exercise requires the ability to sustain focus on a part of the body. Students are reminded not to judge themselves if their attention strays from the area of focus and to gently bring their attention back. The exercise also requires the ability to shift attention when students are asked to move their attention to the next body area (Anderson et al., 2007; Bishop et al., 2004; Wallace \& Shapiro, 2006). Students will also be taught a sitting meditation. During the sitting meditation process, participants consciously sit with an erect body posture. Their heads, necks, and backs are aligned, which allows the breath to flow easier (Kabat-Zinn, 1990). When practicing meditation formally, participants may sit in a chair or on the floor. As the mind becomes restless, participants are encouraged to gently but firmly bring their attention back to breathing or the belly. This practice trains the mind to be less reactive and more stable (Kabat-Zinn, 1990). Homework for the first two weeks is to practice body scans and sitting meditations every day for 20-30 minutes.

\section{Weeks 3 and 4}

Briefly review the material covered during the first session, and offer to answer any questions and difficulties participants may have with regards to MBSR. Teach participants various hatha yoga postures and practice them in class. Hatha yoga is a gentle form of exercise made up of stretching and strengthening postures. Each posture is done very slowly with moment.-to-moment awareness of one's breathing and sensations throughout one's entire body. As the participant learns to work at his or her limits with patience, he or she is able to transform "exercise" into "meditation." Participants slowly learn to bring awareness to the body's limits, which tend to dissolve over time (Kabat-Zinn, 1990). Kabat-Zinn (1990) proposes that when students move themselves into yoga postures, an immediate impact on their mental and emotional states occurs. That is, when students intentionally assume a physical posture that they normally do not hold during the day, students literally changes their inner mental perspective at the same time. Homework involves alternating body scans with yoga postures and mindful breathing for 15-20 minutes per day. In addition, in week 3, participants are required to keep track of one pleasant event per day as it is happening. In week 4, participants should do the same thing for one unpleasant or stressful event per day. 
Briefly review the material covered during the first session, and offer to answer any questions and difficulties participants may have with regards to MBSR. Practice a sitting meditation. Participants will gradually expand their field of awareness from the breath, to other bodily sensations, sounds, thoughts and feelings, or no particular object. Homework involves alternating 30 minutes of yoga practice (or a body scan) with sitting meditations.

\section{Week 7}

Briefly review the material covered during the first session, and offer to answer any questions and difficulties participants may have with regards to MBSR. In this class, the practice is self..'guided. Participants are encouraged to decide on the mix of practices themselves. Homework involves experimentation on the duration and combination of techniques that they prefer, as long as it lasts for at least 30 minutes.

Week 8

Briefly review the material covered during the first session, and offer to answer any questions and difficulties participants may have with regards to MBSR. This session involves structured practice led by group leader. At the end of the session, solicit feedback from group members about their experiences with MBSR. Thank participants for their commitment to the program. 


\section{Appendix E Reading/Relaxation Protocol \\ Progressive Muscle Relaxation Protocol (Bernstein \& Borkvec, 1973)}

Week 1 - Introduce the participants to PMR and conduct 16"-muscle-group PMR protocol. Following practice, troubleshoot difficulties relaxing and offer to answer any questions from participants about PMR. At the end of the first session, discuss the importance of home practice of relaxation skills. Provide PMR practice compact disc containing 4 PMR protocols: a 16-muscle-group PMR protocol, an 8-muscle group protocol, a 4-muscle-group protocol, and a recall relaxation protocol. Instruct participants to practice using the 16-muscle-.group protocol for the coming week.

Week 2 - Briefly review the material covered during the first session, and offer to answer any questions and difficulties participants may have about PMR. Next, lead participants in practice of PMR using the 16-muscle-group relaxation protocol. At the end of the second session, discuss any participant questions or concerns, troubleshooting difficulties relaxing. Reiterate the importance of continued practice of relaxation skills.

Week 3 - Offer to answer any remaining questions about relaxation practice. Discuss any difficulties with home practice of PMR. To encourage continued practice, also solicit examples of successful at:-home relaxation practice from group members. Next, lead participants in practice of PMR using the 16-muscle-group relaxation protocol. At the end of the session, reiterate the importance of continued practice of relaxation skills.

Week 4 - Begin by offering to answer any remaining questions about relaxation practice. Discuss any difficulties with home practice of PMR. To encourage continued practice, also solicit examples of successful at-"home relaxation practice from group members at this time. Then introduce the 8-muscle..-group PMR protocol, and engage participants in relaxation practice using this 8-muscle-"group PMR protocol. At the end of the session, reiterate the importance of continued practice of relaxation skills.

Week 5 - Begin by offering to answer any remaining questions about relaxation practice. Discuss any difficulties with home practice of PMR. To encourage continued practice, also solicit examples of successful at-"home relaxation practice from group members at this time. Next, lead participants in practice of PMR using the 8*-muscle-group-relaxation protocol. At the end of the session, reiterate the importance of continued practice of relaxation skills.

Week 6 - Begin by offering to answer any remaining questions about relaxation practice. Discuss any difficulties with home practice of PMR. To encourage continued practice, also solicit examples of successful at-"home relaxation practice from group members at this time. Then introduce the 4-muscle--group PMR protocol, and engage participants in relaxation practice using this brief PMR protocol. At the end of the session, reiterate the importance of continued practice of relaxation skills. 
Week 7 - Begin by offering to answer any remaining questions about relaxation practice. Discuss any difficulties with home practice of PMR. To encourage continued practice, also solicit examples of successful at-"home relaxation practice from group members at this time. Next, lead participants in practice of 4-muscle-groups PMR. At the end of the session, reiterate the importance of continued practice of relaxation skills.

Week 8 - Begin by offering to answer any remaining questions about relaxation practice. Discuss any difficulties with home practice of PMR. Introduce the final independent-practice protocol and engage participants in relaxation practice using this PMR protocol. At the end of the session, solicit feedback from group members about their experiences with PMR. Thank participants for their commitment to the program.

\section{Links to Short Stories}

http://www.classicshorts.com/stories/lamb.html http://www.classicshorts.com/stories/botd.html http://www.nexuslearning.net/books/holtweol2/collection\%203/landlady.htm http://www.classicshorts.com/stories/tec.html http://www.classicshorts.com/stories/mislaid.html http://www.classicshorts.com/stories/shootelp.html http://www.classicshorts.com/stories/tiger.html http://www.online-literature.com/poe/177/ 


\section{APPENDIX F \\ Day-to-Day Experiences}

Instructions: Below is a collection of statements about your everyday experience. Using the 1-6 scale below, please indicate how frequently or infrequently you currently have each experience. Please answer according to what really reflects your experience rather than what you think your experience should be. Please treat each item separately from every other item.

$\begin{array}{cccccc}1 & 2 & 3 & 4 & 5 & 6 \\ \text { Almost } & \text { Very } & \text { Somewhat } & \text { Somewhat } & \text { Very } & \text { Almost } \\ \text { Always } & \text { Frequently } & \text { Frequently } & \text { Infrequently } & \text { Infrequently } & \text { Never }\end{array}$

I could be experiencing some emotion and not be conscious of it until some time later.

I break or spill things because of carelessness, not paying attention, or thinking of something else.

I find it difficult to stay focused on what's happening in the present.

I tend to walk quickly to get where I'm going without paying attention to what I experience along the way.

I tend not to notice feelings of physical tension or discomfort until they really grab my attention.

I forget a person's name almost as soon as I've been told it for the first time.

It seems I am "running on automatic," without much awareness of what I'm doing.

I rush through activities without being really attentive to them.

I get so focused on the goal I want to achieve that I lose touch with what I'm doing right now to get there.

I do jobs or tasks automatically, without being aware of what I'm doing.

I find myself listening to someone with one ear, doing something else at the same time.

I drive places on 'automatic pilot' and then wonder why I went there.

I find myself preoccupied with the future or the past.

\begin{tabular}{|c|c|c|c|c|}
\hline 1 & 2 & 3 & 4 & 5 \\
\hline 1 & 2 & 3 & 4 & 5 \\
\hline 1 & 2 & 3 & 4 & 5 \\
\hline 1 & 2 & 3 & 4 & 5 \\
\hline 1 & 2 & 3 & 4 & 5 \\
\hline 1 & 2 & 3 & 4 & 5 \\
\hline 1 & 2 & 3 & 4 & 5 \\
\hline 1 & 2 & 3 & 4 & 5 \\
\hline 1 & 2 & 3 & 4 & 5 \\
\hline 1 & 2 & 3 & 4 & 5 \\
\hline 1 & 2 & 3 & 4 & 5 \\
\hline & 2 & 3 & 4 & 5 \\
\hline 1 & 2 & 3 & 4 & 5 \\
\hline
\end{tabular}




\begin{tabular}{|c|c|c|c|c|c|c|c|c|c|}
\hline $\begin{array}{c}1 \\
\text { Almost } \\
\text { Always }\end{array}$ & $\begin{array}{c}2 \\
\text { Very } \\
\text { Frequently }\end{array}$ & $\begin{array}{c}3 \\
\text { Somewhat } \\
\text { Frequently }\end{array}$ & $\begin{array}{c}4 \\
\text { Somewhat } \\
\text { Infrequently }\end{array}$ & $\begin{array}{r}5 \\
\mathrm{Ve} \\
\text { Infreq }\end{array}$ & & & \multicolumn{2}{|c|}{$\begin{array}{c}6 \\
\text { Almost }\end{array}$} & \\
\hline \multicolumn{4}{|c|}{$\begin{array}{l}\text { I find myself doing things without paying } \\
\text { attention. }\end{array}$} & 1 & 2 & 3 & 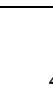 & 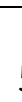 & 6 \\
\hline \multicolumn{4}{|c|}{ I snack without being aware that I'm eating. } & 1 & 2 & 3 & & 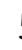 & 6 \\
\hline
\end{tabular}




\section{Perceived Stress Scale}

The questions in this scale ask you about your feelings and thoughts during the last month. In each case, you will be asked to indicate by circling how often you felt or thought a certain way.

Name

Date

Age Gender (Circle): M F

Other

$0=$ Never $\quad 1=$ Almost Never $\quad 2=$ Sometimes

$3=$ Fairly Often

$4=$ Very Often

1. In the last month, how often have you been upset

because of something that happened unexpectedly?

$\begin{array}{lllll}.0 & 1 & 2 & 3 & 4\end{array}$

2. In the last month, how often have you felt that you were unable

to control the important things in your life? $\begin{array}{lllll}0 & 1 & 2 & 3 & 4\end{array}$

3. In the last month, how often have you felt nervous and "stressed"? $\begin{array}{lllll}0 & 1 & 2 & 3 & 4\end{array}$

4. In the last month, how often have you felt confident about your ability to handle your personal problems?

5. In the last month, how often have you felt that things were going your way? $\begin{array}{lllll}0 & 1 & 2 & 3 & 4\end{array}$

6. In the last month, how often have you found that you could not cope with all the things that you had to do? $\begin{array}{lllll}0 & 1 & 2 & 3 & 4\end{array}$

7. In the last month, how often have you been able to control irritations in your life? $\begin{array}{lllll}0 & 1 & 2 & 3 & 4\end{array}$

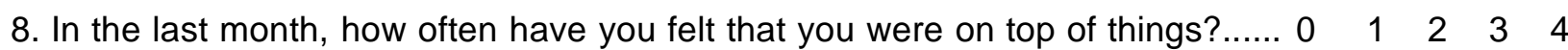

9. In the last month, how often have you been angered because of things that were outside of your control?

10. In the last month, how often have you felt difficulties were piling up so high that you could not overcome them? 
CODE:

DATE:

GDS: SELF-RATING SCALE

1. Are you basically satisfied with your life?

YES / NO

2. Have you dropped many of your activities and interests

YES / NO

3 . Do you feel that your life is empty?

YES / NO

4. Do you often get bored?

YES / NO

5. Are you hopeful about the future?

YES / NO

6. Are you bothered by thought you can't get out of your head?

YES / NO

7. Are you in good spirits most of the time?

YES / NO

8. Are you afraid that something bad is going to happen to you?

YES / NO

9. Do you feel happy most of the time?

YES / NO

10. Do you often feel helpless?

YES / NO

11. Do you often get restless and fidgety?

12. Do you prefer to stay home, rather than going out and doing

YES / NO new things?

13. Do you frequently worry about the future?

YES / NO

14. Do you feel you have more problems with memory than most?

YES / NO

15. Do you think it is wonderful to be alive now?

YES / NO

16. Do you often feel downhearted and blue?

YES / NO

17. Do you feel pretty worthless the way you are now?

YES / NO

18. Do you worry a lot about the past?

YES / NO

19. Do you find life very exciting?

20. Is it hard for you to get started on new projects?

YES / NO

YES / NO

21. Do you feel full of energy?

YES / NO

22. Do you feel that your situation is hopeless?

YES / NO

23. Do you think that most people are better off than you are?

YES / NO

24. Do you frequently get upset over little things?

YES / NO

25 . Do you frequently feel like crying?

YES / NO

26. Do you have trouble concentrating?

YES / NO

27. Do you enjoy getting up in the morning?

YES / NO

28. Do you prefer to avoid social gatherings?

YES / NO

29. Is it easy for you to make decisions?

YES / NO

30. Is your mind as clear as it used to be?

YES / NO 
CODE:

DATE:

\section{ROSENBERG SCALE OF Self Esteem}

Below is a list of statements dealing with your general feelings about yourself. If you STRONGLY AGREE, circle 0. If you AGREE with the statement, circle 1. If you DISAGREE, circle 2. If you STRONGLY DISAGREE, circle 3.

\begin{tabular}{|c|c|c|c|c|c|}
\hline & & $\begin{array}{l}0 \\
\text { Strongly } \\
\text { Agree }\end{array}$ & $\begin{array}{c}1 \\
\text { Agree }\end{array}$ & $\begin{array}{c}2 \\
\text { Disagree }\end{array}$ & $\begin{array}{c}3 \\
\text { Strongly } \\
\text { Disagree }\end{array}$ \\
\hline 1 & $\begin{array}{l}\text { I feel that I am a person of } \\
\text { worth, at least on an equal } \\
\text { plane with others. }\end{array}$ & 0 & 1 & 2 & 3 \\
\hline 2 & $\begin{array}{l}\text { I feel that I have a number } \\
\text { of good qualities. }\end{array}$ & 0 & 1 & 2 & 3 \\
\hline 3 & $\begin{array}{l}\text { All in all, I am inclined to } \\
\text { feel that I am a failure. }\end{array}$ & 0 & 1 & 2 & 3 \\
\hline 4 & $\begin{array}{l}\text { I am able to do things as } \\
\text { well as other people. }\end{array}$ & 0 & 1 & 2 & 3 \\
\hline 5 & $\begin{array}{l}\text { I feel I do not have much to } \\
\text { be proud of. }\end{array}$ & 0 & 1 & 2 & 3 \\
\hline 6 & $\begin{array}{l}\text { I take a positive attitude } \\
\text { towards myself. }\end{array}$ & 0 & 1 & 2 & 3 \\
\hline 7 & $\begin{array}{l}\text { On the whole, I am satisfied } \\
\text { with myself. }\end{array}$ & 0 & 1 & 2 & 3 \\
\hline 8 & $\begin{array}{l}\text { I wish I could have more } \\
\text { respect for myself. }\end{array}$ & 0 & 1 & 2 & 3 \\
\hline 9 & $\begin{array}{l}\text { I certainly feel useless at } \\
\text { times. }\end{array}$ & 0 & 1 & 2 & 3 \\
\hline 10 & $\begin{array}{l}\text { At times I think I am no } \\
\text { good at all. }\end{array}$ & 0 & 1 & 2 & 3 \\
\hline
\end{tabular}




\section{QUALITY OF LIFE SCALE (QOL)}

Please read each item and circle the number that best describes how satisfied you are at this time. Please answer each item even if you do not currently participate in an activity or have a relationship. You can be satisfied or dissatisfied with not doing the activity or having the relationship.

1. Material comforts home, food,

\begin{tabular}{|c|c|c|c|c|c|c|}
\hline \multicolumn{7}{|c|}{ OF LIFE SCALE (QOL) } \\
\hline \multicolumn{7}{|c|}{$\begin{array}{l}\text { at best describes how satisfied you are at this time. Please } \\
\text { participate in an activity or have a relationship. You can be } \\
\text { ity or having the relationship. }\end{array}$} \\
\hline Delighted & Pleased & $\begin{array}{l}\text { Mostly } \\
\text { Satisfied }\end{array}$ & Mixed & $\begin{array}{c}\text { Mostly } \\
\text { Dissatisfied }\end{array}$ & Unhappy & Terrible \\
\hline 7 & 6 & 5 & 4 & 3 & 2 & 1 \\
\hline 7 & 6 & 5 & 4 & 3 & 2 & 1 \\
\hline 7 & 6 & 5 & 4 & 3 & 2 & 1 \\
\hline 7 & 6 & 5 & 4 & 3 & 2 & 1 \\
\hline 7 & 6 & 5 & 4 & 3 & 2 & 1 \\
\hline 7 & 6 & 5 & 4 & 3 & 2 & 1 \\
\hline 7 & 6 & 5 & 4 & 3 & 2 & 1 \\
\hline 7 & 6 & 5 & 4 & 3 & 2 & 1 \\
\hline 7 & 6 & 5 & 4 & 3 & 2 & 1 \\
\hline 7 & 6 & 5 & 4 & 3 & 2 & 1 \\
\hline
\end{tabular}
conveniences, financial security

2. Health - being physically fit and vigorous

3. Relationships with parents, siblings \& otherrelatives- communicating, visiting,

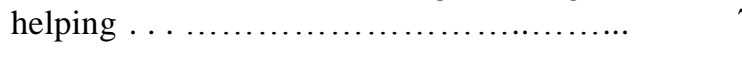

4. Having and rearing children .........

5. Close relationships with spouse or significant other ...............

6. Close friends $\ldots \ldots \ldots \ldots \ldots \ldots \ldots$

7. Helping and encouraging others, volunteering, giving advice $\ldots \ldots \ldots \ldots$

8. Participating in organizations and public affairs ......................

9. Learning- attending school, improving understanding, getting additional

knowledge . .

7

\begin{tabular}{|c|c|c|c|c|c|}
\hline \multicolumn{6}{|c|}{ E SCALE (QOL) } \\
\hline \multicolumn{6}{|c|}{$\begin{array}{l}\text { cribes how satisfied you are at this time. Please } \\
\text { in an activity or have a relationship. You can be } \\
\text { ing the relationship. }\end{array}$} \\
\hline Pleased & $\begin{array}{c}\text { Mostly } \\
\text { Satisfied }\end{array}$ & Mixed & $\begin{array}{c}\text { Mostly } \\
\text { Dissatisfied }\end{array}$ & Unhappy & Terrible \\
\hline 6 & 5 & 4 & 3 & 2 & 1 \\
\hline 6 & 5 & 4 & 3 & 2 & 1 \\
\hline 6 & 5 & 4 & 3 & 2 & 1 \\
\hline 6 & 5 & 4 & 3 & 2 & 1 \\
\hline 6 & 5 & 4 & 3 & 2 & 1 \\
\hline 6 & 5 & 4 & 3 & 2 & 1 \\
\hline 6 & 5 & 4 & 3 & 2 & 1 \\
\hline 6 & 5 & 4 & 3 & 2 & 1 \\
\hline 6 & 5 & 4 & 3 & 2 & 1 \\
\hline 6 & 5 & 4 & 3 & 2 & 1 \\
\hline
\end{tabular}
5

4

3

2

1

10. Understanding yourself - knowing your assets and limitations - knowing what life

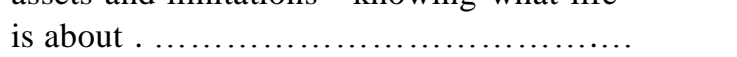

11. Work - job or in home ...........

12. Expressing yourself creatively .......

13. Socializing - meeting other people, doing things, parties, etc ...........

14. Reading, listening to music, or observing entertainment ..........

15. Participating in active recreation .....

16. Independence, doing for yourself ...... .

7

\begin{tabular}{|c|c|c|c|c|c|}
\hline \multicolumn{6}{|c|}{ E SCALE (QOL) } \\
\hline \multicolumn{6}{|c|}{$\begin{array}{l}\text { cribes how satisfied you are at this time. Please } \\
\text { in an activity or have a relationship. You can be } \\
\text { ing the relationship. }\end{array}$} \\
\hline Pleased & $\begin{array}{c}\text { Mostly } \\
\text { Satisfied }\end{array}$ & Mixed & $\begin{array}{c}\text { Mostly } \\
\text { Dissatisfied }\end{array}$ & Unhappy & Terrible \\
\hline 6 & 5 & 4 & 3 & 2 & 1 \\
\hline 6 & 5 & 4 & 3 & 2 & 1 \\
\hline 6 & 5 & 4 & 3 & 2 & 1 \\
\hline 6 & 5 & 4 & 3 & 2 & 1 \\
\hline 6 & 5 & 4 & 3 & 2 & 1 \\
\hline 6 & 5 & 4 & 3 & 2 & 1 \\
\hline 6 & 5 & 4 & 3 & 2 & 1 \\
\hline 6 & 5 & 4 & 3 & 2 & 1 \\
\hline 6 & 5 & 4 & 3 & 2 & 1 \\
\hline 6 & 5 & 4 & 3 & 2 & 1 \\
\hline
\end{tabular}

\begin{tabular}{|c|c|c|c|c|c|}
\hline \multicolumn{6}{|c|}{ E SCALE (QOL) } \\
\hline \multicolumn{6}{|c|}{$\begin{array}{l}\text { cribes how satisfied you are at this time. Please } \\
\text { in an activity or have a relationship. You can be } \\
\text { ing the relationship. }\end{array}$} \\
\hline Pleased & $\begin{array}{c}\text { Mostly } \\
\text { Satisfied }\end{array}$ & Mixed & $\begin{array}{c}\text { Mostly } \\
\text { Dissatisfied }\end{array}$ & Unhappy & Terrible \\
\hline 6 & 5 & 4 & 3 & 2 & 1 \\
\hline 6 & 5 & 4 & 3 & 2 & 1 \\
\hline 6 & 5 & 4 & 3 & 2 & 1 \\
\hline 6 & 5 & 4 & 3 & 2 & 1 \\
\hline 6 & 5 & 4 & 3 & 2 & 1 \\
\hline 6 & 5 & 4 & 3 & 2 & 1 \\
\hline 6 & 5 & 4 & 3 & 2 & 1 \\
\hline 6 & 5 & 4 & 3 & 2 & 1 \\
\hline 6 & 5 & 4 & 3 & 2 & 1 \\
\hline 6 & 5 & 4 & 3 & 2 & 1 \\
\hline
\end{tabular}

4

3

2

1

7

\begin{tabular}{|c|c|c|c|c|c|}
\hline \multicolumn{6}{|c|}{ E SCALE (QOL) } \\
\hline \multicolumn{6}{|c|}{$\begin{array}{l}\text { cribes how satisfied you are at this time. Please } \\
\text { in an activity or have a relationship. You can be } \\
\text { ing the relationship. }\end{array}$} \\
\hline Pleased & $\begin{array}{c}\text { Mostly } \\
\text { Satisfied }\end{array}$ & Mixed & $\begin{array}{c}\text { Mostly } \\
\text { Dissatisfied }\end{array}$ & Unhappy & Terrible \\
\hline 6 & 5 & 4 & 3 & 2 & 1 \\
\hline 6 & 5 & 4 & 3 & 2 & 1 \\
\hline 6 & 5 & 4 & 3 & 2 & 1 \\
\hline 6 & 5 & 4 & 3 & 2 & 1 \\
\hline 6 & 5 & 4 & 3 & 2 & 1 \\
\hline 6 & 5 & 4 & 3 & 2 & 1 \\
\hline 6 & 5 & 4 & 3 & 2 & 1 \\
\hline 6 & 5 & 4 & 3 & 2 & 1 \\
\hline 6 & 5 & 4 & 3 & 2 & 1 \\
\hline 6 & 5 & 4 & 3 & 2 & 1 \\
\hline
\end{tabular}

\begin{tabular}{|c|c|c|c|c|c|}
\hline \multicolumn{6}{|c|}{ E SCALE (QOL) } \\
\hline \multicolumn{6}{|c|}{$\begin{array}{l}\text { cribes how satisfied you are at this time. Please } \\
\text { in an activity or have a relationship. You can be } \\
\text { ing the relationship. }\end{array}$} \\
\hline Pleased & $\begin{array}{c}\text { Mostly } \\
\text { Satisfied }\end{array}$ & Mixed & $\begin{array}{c}\text { Mostly } \\
\text { Dissatisfied }\end{array}$ & Unhappy & Terrible \\
\hline 6 & 5 & 4 & 3 & 2 & 1 \\
\hline 6 & 5 & 4 & 3 & 2 & 1 \\
\hline 6 & 5 & 4 & 3 & 2 & 1 \\
\hline 6 & 5 & 4 & 3 & 2 & 1 \\
\hline 6 & 5 & 4 & 3 & 2 & 1 \\
\hline 6 & 5 & 4 & 3 & 2 & 1 \\
\hline 6 & 5 & 4 & 3 & 2 & 1 \\
\hline 6 & 5 & 4 & 3 & 2 & 1 \\
\hline 6 & 5 & 4 & 3 & 2 & 1 \\
\hline 6 & 5 & 4 & 3 & 2 & 1 \\
\hline
\end{tabular}

\begin{tabular}{|c|c|c|c|c|c|}
\hline \multicolumn{6}{|c|}{ E SCALE (QOL) } \\
\hline \multicolumn{6}{|c|}{$\begin{array}{l}\text { cribes how satisfied you are at this time. Please } \\
\text { in an activity or have a relationship. You can be } \\
\text { ing the relationship. }\end{array}$} \\
\hline Pleased & $\begin{array}{c}\text { Mostly } \\
\text { Satisfied }\end{array}$ & Mixed & $\begin{array}{c}\text { Mostly } \\
\text { Dissatisfied }\end{array}$ & Unhappy & Terrible \\
\hline 6 & 5 & 4 & 3 & 2 & 1 \\
\hline 6 & 5 & 4 & 3 & 2 & 1 \\
\hline 6 & 5 & 4 & 3 & 2 & 1 \\
\hline 6 & 5 & 4 & 3 & 2 & 1 \\
\hline 6 & 5 & 4 & 3 & 2 & 1 \\
\hline 6 & 5 & 4 & 3 & 2 & 1 \\
\hline 6 & 5 & 4 & 3 & 2 & 1 \\
\hline 6 & 5 & 4 & 3 & 2 & 1 \\
\hline 6 & 5 & 4 & 3 & 2 & 1 \\
\hline 6 & 5 & 4 & 3 & 2 & 1 \\
\hline
\end{tabular}

\begin{tabular}{|c|c|c|c|c|c|}
\hline \multicolumn{6}{|c|}{ E SCALE (QOL) } \\
\hline \multicolumn{6}{|c|}{$\begin{array}{l}\text { cribes how satisfied you are at this time. Please } \\
\text { in an activity or have a relationship. You can be } \\
\text { ing the relationship. }\end{array}$} \\
\hline Pleased & $\begin{array}{c}\text { Mostly } \\
\text { Satisfied }\end{array}$ & Mixed & $\begin{array}{c}\text { Mostly } \\
\text { Dissatisfied }\end{array}$ & Unhappy & Terrible \\
\hline 6 & 5 & 4 & 3 & 2 & 1 \\
\hline 6 & 5 & 4 & 3 & 2 & 1 \\
\hline 6 & 5 & 4 & 3 & 2 & 1 \\
\hline 6 & 5 & 4 & 3 & 2 & 1 \\
\hline 6 & 5 & 4 & 3 & 2 & 1 \\
\hline 6 & 5 & 4 & 3 & 2 & 1 \\
\hline 6 & 5 & 4 & 3 & 2 & 1 \\
\hline 6 & 5 & 4 & 3 & 2 & 1 \\
\hline 6 & 5 & 4 & 3 & 2 & 1 \\
\hline 6 & 5 & 4 & 3 & 2 & 1 \\
\hline
\end{tabular}

\begin{tabular}{|c|c|c|c|c|c|}
\hline \multicolumn{6}{|c|}{ E SCALE (QOL) } \\
\hline \multicolumn{6}{|c|}{$\begin{array}{l}\text { cribes how satisfied you are at this time. Please } \\
\text { in an activity or have a relationship. You can be } \\
\text { ing the relationship. }\end{array}$} \\
\hline Pleased & $\begin{array}{c}\text { Mostly } \\
\text { Satisfied }\end{array}$ & Mixed & $\begin{array}{c}\text { Mostly } \\
\text { Dissatisfied }\end{array}$ & Unhappy & Terrible \\
\hline 6 & 5 & 4 & 3 & 2 & 1 \\
\hline 6 & 5 & 4 & 3 & 2 & 1 \\
\hline 6 & 5 & 4 & 3 & 2 & 1 \\
\hline 6 & 5 & 4 & 3 & 2 & 1 \\
\hline 6 & 5 & 4 & 3 & 2 & 1 \\
\hline 6 & 5 & 4 & 3 & 2 & 1 \\
\hline 6 & 5 & 4 & 3 & 2 & 1 \\
\hline 6 & 5 & 4 & 3 & 2 & 1 \\
\hline 6 & 5 & 4 & 3 & 2 & 1 \\
\hline 6 & 5 & 4 & 3 & 2 & 1 \\
\hline
\end{tabular}

\begin{tabular}{|c|c|c|c|c|c|}
\hline \multicolumn{6}{|c|}{ E SCALE (QOL) } \\
\hline \multicolumn{6}{|c|}{$\begin{array}{l}\text { cribes how satisfied you are at this time. Please } \\
\text { in an activity or have a relationship. You can be } \\
\text { ing the relationship. }\end{array}$} \\
\hline Pleased & $\begin{array}{c}\text { Mostly } \\
\text { Satisfied }\end{array}$ & Mixed & $\begin{array}{c}\text { Mostly } \\
\text { Dissatisfied }\end{array}$ & Unhappy & Terrible \\
\hline 6 & 5 & 4 & 3 & 2 & 1 \\
\hline 6 & 5 & 4 & 3 & 2 & 1 \\
\hline 6 & 5 & 4 & 3 & 2 & 1 \\
\hline 6 & 5 & 4 & 3 & 2 & 1 \\
\hline 6 & 5 & 4 & 3 & 2 & 1 \\
\hline 6 & 5 & 4 & 3 & 2 & 1 \\
\hline 6 & 5 & 4 & 3 & 2 & 1 \\
\hline 6 & 5 & 4 & 3 & 2 & 1 \\
\hline 6 & 5 & 4 & 3 & 2 & 1 \\
\hline 6 & 5 & 4 & 3 & 2 & 1 \\
\hline
\end{tabular}

7

\begin{tabular}{|c|c|c|c|c|c|}
\hline \multicolumn{6}{|c|}{ E SCALE (QOL) } \\
\hline \multicolumn{6}{|c|}{$\begin{array}{l}\text { cribes how satisfied you are at this time. Please } \\
\text { in an activity or have a relationship. You can be } \\
\text { ing the relationship. }\end{array}$} \\
\hline Pleased & $\begin{array}{c}\text { Mostly } \\
\text { Satisfied }\end{array}$ & Mixed & $\begin{array}{c}\text { Mostly } \\
\text { Dissatisfied }\end{array}$ & Unhappy & Terrible \\
\hline 6 & 5 & 4 & 3 & 2 & 1 \\
\hline 6 & 5 & 4 & 3 & 2 & 1 \\
\hline 6 & 5 & 4 & 3 & 2 & 1 \\
\hline 6 & 5 & 4 & 3 & 2 & 1 \\
\hline 6 & 5 & 4 & 3 & 2 & 1 \\
\hline 6 & 5 & 4 & 3 & 2 & 1 \\
\hline 6 & 5 & 4 & 3 & 2 & 1 \\
\hline 6 & 5 & 4 & 3 & 2 & 1 \\
\hline 6 & 5 & 4 & 3 & 2 & 1 \\
\hline 6 & 5 & 4 & 3 & 2 & 1 \\
\hline
\end{tabular}

\begin{tabular}{|c|c|c|c|c|c|}
\hline \multicolumn{6}{|c|}{ E SCALE (QOL) } \\
\hline \multicolumn{6}{|c|}{$\begin{array}{l}\text { cribes how satisfied you are at this time. Please } \\
\text { in an activity or have a relationship. You can be } \\
\text { ing the relationship. }\end{array}$} \\
\hline Pleased & $\begin{array}{c}\text { Mostly } \\
\text { Satisfied }\end{array}$ & Mixed & $\begin{array}{c}\text { Mostly } \\
\text { Dissatisfied }\end{array}$ & Unhappy & Terrible \\
\hline 6 & 5 & 4 & 3 & 2 & 1 \\
\hline 6 & 5 & 4 & 3 & 2 & 1 \\
\hline 6 & 5 & 4 & 3 & 2 & 1 \\
\hline 6 & 5 & 4 & 3 & 2 & 1 \\
\hline 6 & 5 & 4 & 3 & 2 & 1 \\
\hline 6 & 5 & 4 & 3 & 2 & 1 \\
\hline 6 & 5 & 4 & 3 & 2 & 1 \\
\hline 6 & 5 & 4 & 3 & 2 & 1 \\
\hline 6 & 5 & 4 & 3 & 2 & 1 \\
\hline 6 & 5 & 4 & 3 & 2 & 1 \\
\hline
\end{tabular}

7

\begin{tabular}{|c|c|c|c|c|c|}
\hline \multicolumn{6}{|c|}{ E SCALE (QOL) } \\
\hline \multicolumn{6}{|c|}{$\begin{array}{l}\text { cribes how satisfied you are at this time. Please } \\
\text { in an activity or have a relationship. You can be } \\
\text { ing the relationship. }\end{array}$} \\
\hline Pleased & $\begin{array}{c}\text { Mostly } \\
\text { Satisfied }\end{array}$ & Mixed & $\begin{array}{c}\text { Mostly } \\
\text { Dissatisfied }\end{array}$ & Unhappy & Terrible \\
\hline 6 & 5 & 4 & 3 & 2 & 1 \\
\hline 6 & 5 & 4 & 3 & 2 & 1 \\
\hline 6 & 5 & 4 & 3 & 2 & 1 \\
\hline 6 & 5 & 4 & 3 & 2 & 1 \\
\hline 6 & 5 & 4 & 3 & 2 & 1 \\
\hline 6 & 5 & 4 & 3 & 2 & 1 \\
\hline 6 & 5 & 4 & 3 & 2 & 1 \\
\hline 6 & 5 & 4 & 3 & 2 & 1 \\
\hline 6 & 5 & 4 & 3 & 2 & 1 \\
\hline 6 & 5 & 4 & 3 & 2 & 1 \\
\hline
\end{tabular}

\begin{tabular}{|c|c|c|c|c|c|}
\hline \multicolumn{6}{|c|}{ E SCALE (QOL) } \\
\hline \multicolumn{6}{|c|}{$\begin{array}{l}\text { cribes how satisfied you are at this time. Please } \\
\text { in an activity or have a relationship. You can be } \\
\text { ing the relationship. }\end{array}$} \\
\hline Pleased & $\begin{array}{c}\text { Mostly } \\
\text { Satisfied }\end{array}$ & Mixed & $\begin{array}{c}\text { Mostly } \\
\text { Dissatisfied }\end{array}$ & Unhappy & Terrible \\
\hline 6 & 5 & 4 & 3 & 2 & 1 \\
\hline 6 & 5 & 4 & 3 & 2 & 1 \\
\hline 6 & 5 & 4 & 3 & 2 & 1 \\
\hline 6 & 5 & 4 & 3 & 2 & 1 \\
\hline 6 & 5 & 4 & 3 & 2 & 1 \\
\hline 6 & 5 & 4 & 3 & 2 & 1 \\
\hline 6 & 5 & 4 & 3 & 2 & 1 \\
\hline 6 & 5 & 4 & 3 & 2 & 1 \\
\hline 6 & 5 & 4 & 3 & 2 & 1 \\
\hline 6 & 5 & 4 & 3 & 2 & 1 \\
\hline
\end{tabular}

\begin{tabular}{|c|c|c|c|c|c|}
\hline \multicolumn{6}{|c|}{ E SCALE (QOL) } \\
\hline \multicolumn{6}{|c|}{$\begin{array}{l}\text { cribes how satisfied you are at this time. Please } \\
\text { in an activity or have a relationship. You can be } \\
\text { ing the relationship. }\end{array}$} \\
\hline Pleased & $\begin{array}{c}\text { Mostly } \\
\text { Satisfied }\end{array}$ & Mixed & $\begin{array}{c}\text { Mostly } \\
\text { Dissatisfied }\end{array}$ & Unhappy & Terrible \\
\hline 6 & 5 & 4 & 3 & 2 & 1 \\
\hline 6 & 5 & 4 & 3 & 2 & 1 \\
\hline 6 & 5 & 4 & 3 & 2 & 1 \\
\hline 6 & 5 & 4 & 3 & 2 & 1 \\
\hline 6 & 5 & 4 & 3 & 2 & 1 \\
\hline 6 & 5 & 4 & 3 & 2 & 1 \\
\hline 6 & 5 & 4 & 3 & 2 & 1 \\
\hline 6 & 5 & 4 & 3 & 2 & 1 \\
\hline 6 & 5 & 4 & 3 & 2 & 1 \\
\hline 6 & 5 & 4 & 3 & 2 & 1 \\
\hline
\end{tabular}

7

\begin{tabular}{|c|c|c|c|c|c|}
\hline \multicolumn{6}{|c|}{ E SCALE (QOL) } \\
\hline \multicolumn{6}{|c|}{$\begin{array}{l}\text { cribes how satisfied you are at this time. Please } \\
\text { in an activity or have a relationship. You can be } \\
\text { ing the relationship. }\end{array}$} \\
\hline Pleased & $\begin{array}{c}\text { Mostly } \\
\text { Satisfied }\end{array}$ & Mixed & $\begin{array}{c}\text { Mostly } \\
\text { Dissatisfied }\end{array}$ & Unhappy & Terrible \\
\hline 6 & 5 & 4 & 3 & 2 & 1 \\
\hline 6 & 5 & 4 & 3 & 2 & 1 \\
\hline 6 & 5 & 4 & 3 & 2 & 1 \\
\hline 6 & 5 & 4 & 3 & 2 & 1 \\
\hline 6 & 5 & 4 & 3 & 2 & 1 \\
\hline 6 & 5 & 4 & 3 & 2 & 1 \\
\hline 6 & 5 & 4 & 3 & 2 & 1 \\
\hline 6 & 5 & 4 & 3 & 2 & 1 \\
\hline 6 & 5 & 4 & 3 & 2 & 1 \\
\hline 6 & 5 & 4 & 3 & 2 & 1 \\
\hline
\end{tabular}

\begin{tabular}{|c|c|c|c|c|c|}
\hline \multicolumn{6}{|c|}{ E SCALE (QOL) } \\
\hline \multicolumn{6}{|c|}{$\begin{array}{l}\text { cribes how satisfied you are at this time. Please } \\
\text { in an activity or have a relationship. You can be } \\
\text { ing the relationship. }\end{array}$} \\
\hline Pleased & $\begin{array}{c}\text { Mostly } \\
\text { Satisfied }\end{array}$ & Mixed & $\begin{array}{c}\text { Mostly } \\
\text { Dissatisfied }\end{array}$ & Unhappy & Terrible \\
\hline 6 & 5 & 4 & 3 & 2 & 1 \\
\hline 6 & 5 & 4 & 3 & 2 & 1 \\
\hline 6 & 5 & 4 & 3 & 2 & 1 \\
\hline 6 & 5 & 4 & 3 & 2 & 1 \\
\hline 6 & 5 & 4 & 3 & 2 & 1 \\
\hline 6 & 5 & 4 & 3 & 2 & 1 \\
\hline 6 & 5 & 4 & 3 & 2 & 1 \\
\hline 6 & 5 & 4 & 3 & 2 & 1 \\
\hline 6 & 5 & 4 & 3 & 2 & 1 \\
\hline 6 & 5 & 4 & 3 & 2 & 1 \\
\hline
\end{tabular}

\begin{tabular}{|c|c|c|c|c|c|}
\hline \multicolumn{6}{|c|}{ E SCALE (QOL) } \\
\hline \multicolumn{6}{|c|}{$\begin{array}{l}\text { cribes how satisfied you are at this time. Please } \\
\text { in an activity or have a relationship. You can be } \\
\text { ing the relationship. }\end{array}$} \\
\hline Pleased & $\begin{array}{c}\text { Mostly } \\
\text { Satisfied }\end{array}$ & Mixed & $\begin{array}{c}\text { Mostly } \\
\text { Dissatisfied }\end{array}$ & Unhappy & Terrible \\
\hline 6 & 5 & 4 & 3 & 2 & 1 \\
\hline 6 & 5 & 4 & 3 & 2 & 1 \\
\hline 6 & 5 & 4 & 3 & 2 & 1 \\
\hline 6 & 5 & 4 & 3 & 2 & 1 \\
\hline 6 & 5 & 4 & 3 & 2 & 1 \\
\hline 6 & 5 & 4 & 3 & 2 & 1 \\
\hline 6 & 5 & 4 & 3 & 2 & 1 \\
\hline 6 & 5 & 4 & 3 & 2 & 1 \\
\hline 6 & 5 & 4 & 3 & 2 & 1 \\
\hline 6 & 5 & 4 & 3 & 2 & 1 \\
\hline
\end{tabular}

\begin{tabular}{|c|c|c|c|c|c|}
\hline \multicolumn{6}{|c|}{ E SCALE (QOL) } \\
\hline \multicolumn{6}{|c|}{$\begin{array}{l}\text { cribes how satisfied you are at this time. Please } \\
\text { in an activity or have a relationship. You can be } \\
\text { ing the relationship. }\end{array}$} \\
\hline Pleased & $\begin{array}{c}\text { Mostly } \\
\text { Satisfied }\end{array}$ & Mixed & $\begin{array}{c}\text { Mostly } \\
\text { Dissatisfied }\end{array}$ & Unhappy & Terrible \\
\hline 6 & 5 & 4 & 3 & 2 & 1 \\
\hline 6 & 5 & 4 & 3 & 2 & 1 \\
\hline 6 & 5 & 4 & 3 & 2 & 1 \\
\hline 6 & 5 & 4 & 3 & 2 & 1 \\
\hline 6 & 5 & 4 & 3 & 2 & 1 \\
\hline 6 & 5 & 4 & 3 & 2 & 1 \\
\hline 6 & 5 & 4 & 3 & 2 & 1 \\
\hline 6 & 5 & 4 & 3 & 2 & 1 \\
\hline 6 & 5 & 4 & 3 & 2 & 1 \\
\hline 6 & 5 & 4 & 3 & 2 & 1 \\
\hline
\end{tabular}

\begin{tabular}{|c|c|c|c|c|c|}
\hline \multicolumn{6}{|c|}{ E SCALE (QOL) } \\
\hline \multicolumn{6}{|c|}{$\begin{array}{l}\text { cribes how satisfied you are at this time. Please } \\
\text { in an activity or have a relationship. You can be } \\
\text { ing the relationship. }\end{array}$} \\
\hline Pleased & $\begin{array}{c}\text { Mostly } \\
\text { Satisfied }\end{array}$ & Mixed & $\begin{array}{c}\text { Mostly } \\
\text { Dissatisfied }\end{array}$ & Unhappy & Terrible \\
\hline 6 & 5 & 4 & 3 & 2 & 1 \\
\hline 6 & 5 & 4 & 3 & 2 & 1 \\
\hline 6 & 5 & 4 & 3 & 2 & 1 \\
\hline 6 & 5 & 4 & 3 & 2 & 1 \\
\hline 6 & 5 & 4 & 3 & 2 & 1 \\
\hline 6 & 5 & 4 & 3 & 2 & 1 \\
\hline 6 & 5 & 4 & 3 & 2 & 1 \\
\hline 6 & 5 & 4 & 3 & 2 & 1 \\
\hline 6 & 5 & 4 & 3 & 2 & 1 \\
\hline 6 & 5 & 4 & 3 & 2 & 1 \\
\hline
\end{tabular}

\begin{tabular}{|c|c|c|c|c|c|}
\hline \multicolumn{6}{|c|}{ E SCALE (QOL) } \\
\hline \multicolumn{6}{|c|}{$\begin{array}{l}\text { cribes how satisfied you are at this time. Please } \\
\text { in an activity or have a relationship. You can be } \\
\text { ing the relationship. }\end{array}$} \\
\hline Pleased & $\begin{array}{c}\text { Mostly } \\
\text { Satisfied }\end{array}$ & Mixed & $\begin{array}{c}\text { Mostly } \\
\text { Dissatisfied }\end{array}$ & Unhappy & Terrible \\
\hline 6 & 5 & 4 & 3 & 2 & 1 \\
\hline 6 & 5 & 4 & 3 & 2 & 1 \\
\hline 6 & 5 & 4 & 3 & 2 & 1 \\
\hline 6 & 5 & 4 & 3 & 2 & 1 \\
\hline 6 & 5 & 4 & 3 & 2 & 1 \\
\hline 6 & 5 & 4 & 3 & 2 & 1 \\
\hline 6 & 5 & 4 & 3 & 2 & 1 \\
\hline 6 & 5 & 4 & 3 & 2 & 1 \\
\hline 6 & 5 & 4 & 3 & 2 & 1 \\
\hline 6 & 5 & 4 & 3 & 2 & 1 \\
\hline
\end{tabular}

\begin{tabular}{|c|c|c|c|c|c|}
\hline \multicolumn{6}{|c|}{ E SCALE (QOL) } \\
\hline \multicolumn{6}{|c|}{$\begin{array}{l}\text { cribes how satisfied you are at this time. Please } \\
\text { in an activity or have a relationship. You can be } \\
\text { ing the relationship. }\end{array}$} \\
\hline Pleased & $\begin{array}{c}\text { Mostly } \\
\text { Satisfied }\end{array}$ & Mixed & $\begin{array}{c}\text { Mostly } \\
\text { Dissatisfied }\end{array}$ & Unhappy & Terrible \\
\hline 6 & 5 & 4 & 3 & 2 & 1 \\
\hline 6 & 5 & 4 & 3 & 2 & 1 \\
\hline 6 & 5 & 4 & 3 & 2 & 1 \\
\hline 6 & 5 & 4 & 3 & 2 & 1 \\
\hline 6 & 5 & 4 & 3 & 2 & 1 \\
\hline 6 & 5 & 4 & 3 & 2 & 1 \\
\hline 6 & 5 & 4 & 3 & 2 & 1 \\
\hline 6 & 5 & 4 & 3 & 2 & 1 \\
\hline 6 & 5 & 4 & 3 & 2 & 1 \\
\hline 6 & 5 & 4 & 3 & 2 & 1 \\
\hline
\end{tabular}

\begin{tabular}{|c|c|c|c|c|c|}
\hline \multicolumn{6}{|c|}{ E SCALE (QOL) } \\
\hline \multicolumn{6}{|c|}{$\begin{array}{l}\text { cribes how satisfied you are at this time. Please } \\
\text { in an activity or have a relationship. You can be } \\
\text { ing the relationship. }\end{array}$} \\
\hline Pleased & $\begin{array}{c}\text { Mostly } \\
\text { Satisfied }\end{array}$ & Mixed & $\begin{array}{c}\text { Mostly } \\
\text { Dissatisfied }\end{array}$ & Unhappy & Terrible \\
\hline 6 & 5 & 4 & 3 & 2 & 1 \\
\hline 6 & 5 & 4 & 3 & 2 & 1 \\
\hline 6 & 5 & 4 & 3 & 2 & 1 \\
\hline 6 & 5 & 4 & 3 & 2 & 1 \\
\hline 6 & 5 & 4 & 3 & 2 & 1 \\
\hline 6 & 5 & 4 & 3 & 2 & 1 \\
\hline 6 & 5 & 4 & 3 & 2 & 1 \\
\hline 6 & 5 & 4 & 3 & 2 & 1 \\
\hline 6 & 5 & 4 & 3 & 2 & 1 \\
\hline 6 & 5 & 4 & 3 & 2 & 1 \\
\hline
\end{tabular}

7




\section{Feedback Questionnaire}

Please let us know what you thought about the group facilitator:

Facilitator established good rapport by demonstrating:

\section{Genuineness}

\begin{tabular}{lllllll}
0 & 1 & 2 & 3 & 4 & 5 & 6 \\
\hline Poor & $\begin{array}{l}\text { Barely } \\
\text { Adequate }\end{array}$ & Mediocre & $\begin{array}{l}\text { Satis- } \\
\text { factory }\end{array}$ & Good & Very Good & Excellent
\end{tabular}

\section{Warmth}

\begin{tabular}{lllllll}
0 & 1 & 2 & 3 & 4 & 5 & 6 \\
\hline Poor & $\begin{array}{l}\text { Barely } \\
\text { Adequate }\end{array}$ & Mediocre & $\begin{array}{l}\text { Satis- } \\
\text { factory }\end{array}$ & Good & Very Good & Excellent
\end{tabular}

\section{Accurate Empathy}

\begin{tabular}{lllllll}
0 & 1 & 2 & 3 & 4 & 5 & 6 \\
\hline Poor & $\begin{array}{l}\text { Barely } \\
\text { Adequate }\end{array}$ & Mediocre & $\begin{array}{l}\text { Satis- } \\
\text { factory }\end{array}$ & Good & Very Good & Excellent
\end{tabular}

4. Facilitator engaged with participants in a professional manner.

\begin{tabular}{lllllll}
0 & 1 & 2 & 3 & 4 & 5 & 6 \\
\hline Poor & $\begin{array}{l}\text { Barely } \\
\text { Adequate }\end{array}$ & Mediocre & $\begin{array}{l}\text { Satis- } \\
\text { factory }\end{array}$ & Good & Very Good & Excellent
\end{tabular}

5. Facilitator structured class time efficiently, and was able to keep the focus of the session.

\begin{tabular}{lllllll}
0 & 1 & 2 & 3 & 4 & 5 & 6 \\
\hline Poor & $\begin{array}{l}\text { Barely } \\
\text { Adequate }\end{array}$ & Mediocre & $\begin{array}{l}\text { Satis- } \\
\text { factory }\end{array}$ & Good & Very Good & Excellent
\end{tabular}

6. Facilitator elicited feedback about the participants' reactions to the course material.

\begin{tabular}{lllllll}
0 & 1 & 2 & 3 & 4 & 5 & 6 \\
\hline Poor & $\begin{array}{l}\text { Barely } \\
\text { Adequate }\end{array}$ & Mediocre & $\begin{array}{l}\text { Satis- } \\
\text { factory }\end{array}$ & Good & Very Good & Excellent
\end{tabular}


7. Facilitator assigned homework in a clear and specific manner.

\begin{tabular}{lllllll}
0 & 1 & 2 & 3 & 4 & 5 & 6 \\
\hline Poor & $\begin{array}{l}\text { Barely } \\
\text { Adequate }\end{array}$ & Mediocre & $\begin{array}{l}\text { Satis- } \\
\text { factory }\end{array}$ & Good & Very Good & Excellent
\end{tabular}

8. Facilitator asked participants about anticipated problems with completing homework, and problem solved to resolve them.

\begin{tabular}{lllllll}
0 & 1 & 2 & 3 & 4 & 5 & 6 \\
\hline Poor & $\begin{array}{l}\text { Barely } \\
\text { Adequate }\end{array}$ & Mediocre & $\begin{array}{l}\text { Satis- } \\
\text { factory }\end{array}$ & Good & Very Good & Excellent
\end{tabular}




\section{Appendix G}

MBSR Treatment Adherence Checklist

Date:

Week

Class lasted 2.5-3 hours in duration

Body Scan Meditation

Sitting Meditation

Walking Meditation

Gentle Hatha Yoga

Discussion of pleasant/unpleasant events

Discussion of deliberate awareness of routine activities (e.g., eating, driving,

brushing teeth)

Assignment of homework

Formal Practice for 6 days a week Informal Practice for 6 days a week

Individual/Group discussion about homework

Reading \& Relaxation Treatment Adherence Checklist

Date:

Week

Class lasted 2.5-3 hours in duration

1-hour discussion of short story

5-minute break

1-hour PMR

16-muscle groups

8--muscle groups

4-muscle groups

Diaphragmatic breathing

Assignment of homework

Read the short story

Practice PMR

Individual/Group discussion about homework 


\section{References}

Agee, J. D., Danoff-Burg, S., \& Grant, C. A. (2009). Comparing brief stress management courses in a community sample: Mindfulness skills and progressive muscle relaxation. Explore: The Journal of Science and Healing, 5, 104-109. doi: 10.1016/j.explore.2008.12.004

Anderson, N. D., Lau, M. A., Segal, Z. V., \& Bishop, S. R. (2007). Mindfulness-based stress reduction and attentional control. Clinical Psychology \& Psychotherapy, 14, 449-463. doi: 10.1002/cpp.544

Anderson-Hanley, C., Arciero, P. J., Brickman, A. M., Nimon, J. P., Okuma, N., Westen, S. C., ... \& Zimmerman, E. A. (2012). Exergaming and older adult cognition. American Journal of Preventive Medicine, 42, 109-119. doi: 10.1016/j.amepre.2011.10.016

Andres, P., Guerrini, C., Phillips, L. H., \& Perfect, T. J. (2008). Differential effects of aging on executive and automatic inhibition. Developmental Neuropsychology, 33, 101-123. doi: 1080/87565640701884212

Ashendorf, L., Jefferson, A. L., O’Connor, M. K., Chaisson, C., Green, R. C., \& Stern, R. A. (2008). Trail Making Test errors in normal aging, mild cognitive impairment, and dementia. Archives of Clinical Neuropsychology, 23, 129-137. doi:

10.1016/j.acn.2007.11.005

Astin, J. A. (1997). Stress reduction through mindfulness meditation: Effects on psychological symptomatology, sense of control, and spiritual experiences. Journal of Psychotherapy and Psychosomatics, 66, 97-106. doi:

$10.1159 / 000289116$ 
Azulay, J., Smart, C. M., Mott, T., \& Cicerone, K. D. (2012). A pilot study examining the effect of mindfulness-based stress reduction on symptoms of chronic mild traumatic brain injury/postconcussive syndrome. The Journal of Head Trauma Rehabilitation, 1, 1-9. doi: 10.1097/HTR.0b013e318250ebda

Baer, R. A. (2003). Mindfulness training as a clinical intervention: A conceptual and empirical review. Clinical Psychology: Science \& Practice, 10, 125-143. 10.1093/clipsy.bpg015

Barry, D., Bates, M. E., \& Labouvie, E. (2008). FAS and CFL forms of verbal fluency differ in difficulty: A meta-analytic study. Applied Neuropsychology, 15, 97-106. doi: $10.1080 / 09084280802083863$

Bauer, M. E., Vedhara, K., Perks, P., Wilcock, G. K., Lightman, S. L., \& Shanks, N. (2000). Chronic stress in caregivers of dementia patients is associated with reduced lymphocyte sensitivity to glucocorticoids. Journal of Neuroimmunology, 103, 84-92. doi: 10.1016/S0165-5728(99)00228-3

Bergdahl, J., \& Bergdahl, M. (2002). Perceived stress in adults: Prevalence and association of depression, anxiety and medication in a Swedish population. Stress and Health, 18, 235-241. doi: 10.1002/smi.946

Bernstein, D. A., Borkovec, T. D., \& Hazlett-Stevens, H. (2000). New directions in progressive relaxation training: A guidebook for helping professionals. Westport, CT: Praeger.

Bishop, S.R., Lau, M., Shapiro, S., Carlson, L., Anderson, N.D., Carmody, J., ... \& Devins, G. (2004). Mindfulness: A proposed operational definition. Clinical Psychology: Science and Practice, 11, 230-241. doi: 10.1093/clipsy.bph077

Bizon, J. L., Helm, K. A., Han, J. S., Chun, H. J., Pucilowska, J., Lund, P. K., \& Gallagher, M. 
(2001). Hypothalamic-pituitary-adrenal axis function and corticosterone receptor expression in behaviourally characterized young and aged LongEvans rats. European Journal of Neuroscience, 14, 1739-1751. doin: 10.1046/j.0953-816x.2001.01781.x

Bolton, E., Litz, B., Britt, T., Adler, A., \& Roemer, L. (2001). Reports of prior exposure to potentially traumatic events and PTSD in troops poised for deployment. Journal of Traumatic Stress, 14, 249 -256. doi: 10.1023/A:1007864305207

Bonanno, G. A. (2004). Loss, trauma, and human resilience: Have we underestimated the human capacity to thrive after extremely aversive events? American Psychologist, 59, 20-28. doi: 10.1037/0003-066X.59.1.20

Brayne, C., \& Calloway, P. (1990). The association of education and socioeconomic status with the Mini Mental State Examination and the clinical diagnosis of dementia in elderly people. Age \& Ageing, 19, 91-96. doi: 10.1093/ageing/19.2.91

Bremner, J. D., Randall, P., Scott, T. M., Bronen, R. A., Seibyl, Hp. P., Southwick, S. M., ... \& Innis, R. B. (1995). MRI-based measurement of hippocampal volume of patients with combat-related posttraumatic stress disorder. American Journal of Psychiatry, 152(7), 973-981.

Breytspraak, L. M., \& George, L. K. (1979). Measurement of self-concept and selfesteem in older people: State of the art. Experimental Aging Research, 5, 137148.

Brown, K. W., \& Ryan, R. M. (2003). The benefits of being present: mindfulness and its role in psychological well-being. Journal of Personality and Social Psychology, 84, 822-848. doi: 10.1037/0022-3514.84.4.822 
Burckhardt, C. S., Woods, S. L., Schultz, A. A. and Ziebarth, D. M. (1989), Quality of life of adults with chronic illness: A psychometric study. Research in Nursing \& Health, 12, 347-354. doi: 10.1002/nur.4770120604

Cahn-Weiner, D. A., Malloy, P. F., Boyle, P. A., Marran, M., \& Salloway, S. (2000). Prediction of functional status from neuropsychological tests in communitydwelling elderly individuals. Clinical Neuropsychologist, 14, 187-195. doi: $10.1076 / 1385-4046$

Campbell-Sills, L., Cohan, S. L., \& Stein, M. B. (2006). Relationship of resilience to personality, coping, and psychiatric symptoms in young adults. Behaviour Research and Therapy, 44, 585-599. doi: 10.1016/j.brat.2005.05.001

Carlson, L. E., \& Sherwin, B. B. (1998). Steroid hormones, memory and mood in a healthy elderly population. Psychoneuroendocrinology, 23, 583-603. doi: 10.1016/S0306-4530(98)00025-0

Carlson, L. E., Speca, M., Faris, P., \& Patel, K. D. (2007). One year pre-post intervention follow-up of psychological, immune, endocrine and blood pressure outcomes of mindfulness-based stress reduction (MBSR) in breast and prostate cancer outpatients. Brain, Behavior, and Immunity, 21, 1038-1049. doi:

10.1016/j.bbi.2007.04.002

Carlson, L. E., Speca, M., Patel, K. D., \& Goodey, E. (2003). Mindfulness-based stress reduction in relation to quality of life, mood, symptoms of stress, and immune parameters in breast and prostate cancer outpatients. Psychosomatic Medicine, 65, 571-581. doi: 10.1097/01.PSY.0000074003.35911.41

Champagne, D. Dupuy, J-B., Rochford, J., \& Poirier, J. (2002). Apolipoprotein E knockout mice display procedural deficits in the Morris water maze: Analysis 
of learning strategies in three versions of the task. Neuroscience, 114, 641-645. doi: 10.1016/S0306-4522(02)00313-5

Chiesa, A., Calati, R., \& Serretti, A. (2011). Does mindfulness training improve cognitive abilities? A systematic review of neuropsychological findings. Clinical Psychology Review, 31, 449-464. doi: 10.1016/j.cpr.2010.11.003

Coffey, C. E. (2000). Anatomic imaging of the aging human brain. In C. E. Coffey, \& J. L. Cummings (Eds.), Textbook of geriatric neuropsychiatry (2nd ed.) (pp. 181238). Washington, DC: American Psychiatric Press.

Cohen, S. (1986). Contrasting the hassles scale and the perceived stress scale: Who's really measuring appraised stress? American Psychologist, 41, 717-718.

Cohen, S., Kamarch, T., \& Mermelstein, R. (1983). A global measure of perceived stress. Journal of Health and Social Behavior, 24(4), 385-396.

Conrad, C. D. (2008). Chronic stress-induced hippocampal vulnerability: The glucocorticoid vulnerability hypothesis. Nature Reviews Neuroscience, 19(6), 395-411.

Crawley, M. J. (2005). Statistics - An Introduction Using R. West Sussex, UK: John Wiley \& Sons Ltd.

Creswell, J. D., Irwin, M. R., Burklund, L. J., Lieberman, M. D., Arevalo, J. M. G., Ma, J., ... \& Cole, S. W. (2012). Mindfulness-based stress reduction training reduces loneliness and pro-inflammatory gene expression in older adults: A small randomized controlled trial. Brain Behavior and Immunity, 26, 1095-1101. doi: 10.1016/j.bbi.2012.07.006

Delis, D. C., Massman, P. J., Kaplan, E., Mckee, R., Kramer, J. H., \& Gettman, D. (1991). Alternate form of the California Verbal Learning Test: Development and 
reliability. The Clinical Neuropsychologist, 5, 154-162. doi: 10.1080/ 13854049108403299

Du, A. T., Schuff, N., Amend, D., Laakso, M. P., Hsu, Y. Y., Jagust, W. J., ... \& Weiner, M. W. (2001). Magnetic resonance imaging of the entorhinal cortex and hippocampus in mild cognitive impairment and Alzheimer's disease. Journal of Neurology, Neurosurgery, and Psychiatry, 71, 441-447. doi: 10.1136/jnnp.71.4.441

Eslinger, P. J., Damasio, A. R., \& Benton, A. L. (1984). The Iowa Screening Battery for Mental Decline. Iowa City, IA: University of Iowa

Fan, J., McCandliss, B. D., Sommer, T., Raz, ., \& Posner, M. I. (2002). Testing the efficiency and independence of attentional networks. Journal of Cognitive Neuroscience, 14, 340-347. doi: 10.1162/089892902317361886

Feder, A., Nestler, E. J., \& Charney, D. S. (2009). Psychobiology and molecular genetics of resilience. Nature Reviews Neuroscience, 10, 446-457. doi: 10.1038/nrn2649

Feldman, S., Conforti, N., \& Saphier, D. (1990). The preoptic area and bed nucleus of the stria terminalis are involved in the effects of the amygdala on adrenocortical secretion. Neuroscience, 37, 775-779. doi: 10.1016/03064522(90)90107-F

Field, A. P. (2009). Discovering statistics using SPSS: And sex and drugs and rock ' $n$ ' roll (3rd ed.). London: Sage Publications.

Fisher, L. D., Dixon, D. O., Herson, J., Frankowski, R. K., Hearron, M. S., \& Peace, K. E. (1990). Intention to treat in clinical trials. In K. E. Peace (Ed.), Statistical issues in drug research and development (331-350). New York: Marcel Dekker

Flanagan, J. C. (1978). A research approach to improving our quality of life. American Psychologist, 33(2), 138-147. 
Folstein, M. F., Folstein, S. E., \& McHugh, P. R. (1975). Mini-mental state: A practical method for grading the cognitive state of patients for the clinician. Journal of Psychiatric Research, 12, 189-198. doi: 10.1016/0022-3956(75)90026-6

Fontana, L., Partridge, L., \& Longo, V. D. (2010). Extending healthy life span: From yeast to humans. Science, 328, 321-326. doi: 10.1126/science.1172539

Franzen, M. D., Paul, D., \& Iverson, G. L. (1996). Reliability of alternate forms of the Trail Making Test. The Clinical Neuropsychologist, 10, 125-129. doi: $10.1080 / 13854049608406672$

Gallagher-Thompson, D., Shurgot, G. R., Rider, K., Gray, H. L., McKibbin, C. L., .. . Thompson, L. W. (2006). Ethnicity, stress, and cortisol function in Hispanic and non-Hispanic white women: A preliminary study of family dementia caregivers and noncaregivers. The American Journal of Geriatric Psychiatry, 14, 334-342. doi: 10.1097/01.JGP.0000206485.73618.87

Garrido, P. (2011). Aging and stress: Past hypotheses, present approaches and perspectives. Aging and Disease, 2(1), 80-99.

Garrido, P., De Blas, M., del Arco, A., Segovia, G., \& Mora, F. (2010). Aging increases basal but not stress-induced levels of corticosterone in the hippocampus and the prefrontal cortex of the awake rat. Neurobiology of Aging, 33, 375-382. doi: 10.1016/j.neurobiolaging.2010.02.015

Gilboa, A., Shalev, A. Y., Laor, L., Lester, H., Louzoun, Y., Chisin, R., \& Bonne, O. (2004). Functional connectivity of the prefrontal cortex and the amygdala in posttraumatic stress disorder. Biological psychiatry, 55, 263-272. doi: 10.1016/j.biopsych.2003.08.004

Goldin, P. R., \& Gross, J. J. (2010). Effects of mindfulness-based stress reduction 
(MBSR) on emotion regulation in social anxiety disorder. Emotion, 10, 83-91. doi: $10.1037 / \mathrm{a} 0018441$

Goldstein, J. (2002). One dharma: The emerging western Buddhism. San Francisco: HarperCollins.

Grigsby, J., Kaye, K., Baxter, J., Shetterly, S. M., \& Jamman, R. F. (1998). Executive cognitive abilities and functional status among community-dwelling older persons in the San Luis Valley health and aging study. Journal of the American Geriatrics Society, 46(5), 590-596.

Grootendorst, J., de Kloet, E. R., Vossen, C., Dalm, S., \& Oitzl, M. S. (2001). Repeated exposure to rats has persistent genotype-dependent effects on learning and locomotor activity of apolipoprotein E knockout and C57B1/6 mice.

Behavioural Brain Research, 125, 249-259. doi: 10.1016/S01664328(01)00294-7

Grossman, P., Niemann, L., Schmidt, S., \& Walach, H. (2004). Mindfulness-based stress reduction and health benefits: A meta-analysis. Journal of Psychosomatic Research, 57, 35-43. doi: 10.1016/S0022-3999(03)00573-7

Hamarat, D. T., Zabrucky, K. M., Steele, D., Matheny, K. B., Aysan, F. (2001). Perceived stress and coping resource availability as predictors of life satisfaction in young, middle-aged, and older adults. Experimental Aging Research, 27, 181196. doi: $10.1080 / 036107301750074051$

Health Canada. (2002). Canada's aging population. (Catalogue number H39608/2002E). Retrieved May 6, 2013 from Health Canada: http://www.hcsc.gc.ca/seniors-aines

Hennessy, J. W., \& Levine, S. (1979). Stress, arousal, and the pituitary-adrenal system: 
A psychoendocrine hypothesis. In J. M. Sprague \& A. N. Epstein (Eds.), Progress in psychobiology and physiological psychology: Vol. 8. New York, NY: Academic Press

Herman, J. P. \& Cullinan, W. E. (1997). Neurocircuitry of stress: Central control of the hypothalamo-pituitary-adrenocortical axis. Trends in Neuroscience, 20, 78-84. doi: 10.1016/S0166-2236(96)10069-2

Hester, R. L., Kinsella, G. J., Ong, B., \& McGregor, J. (2005). Demographic influences on baseline and derived scores from the Trail Making Test in healthy older Australian adults. The Clinical Neuropsychologist, 19, 45-54. doi: $10.1080 / 13854040490524137$

Hillman, C. H., Erickson, K. I., \& Kramer, A. F. (2008). Be smart, exercise your heart: Exercise effects on brain and cognition. Nature Reviews Neuroscience, 9, 58-65. doi: $10.1038 / \mathrm{nrn} 2298$

Intention to treat analysis and per protocol analysis: Complementary information. (2012). Prescrire International, 21, 304-306. Retrieved from http://www.ncbi.nlm.nih.gov/pubmed/23373104

Issa, A., Rowe, W., Gauthier, S., \& Meaney, M. (1990). Hypothalamic-pituitary-adrenal activity in aged, cognitively impaired and cognitively unimpaired rats. Journal of Neuroscience, $10(10), 3247-3254$.

Jeckel, C. M., Lopes, R. P., Berleze, M. C., Luz, C., Feix, L., Argimon, I. I., . . Bauer, M. E. (2010). Neuroendocrine and immunological correlates of chronic stress in 'strictly healthy' populations. Neuroimmunomodulation, 17, 9-18. doi: $10.1159 / 000243080$

Jedema, H. P., \& Moghaddam, B. (1994). Glutamatergic control of dopamine release 
during stress in the rat prefrontal cortex. Journal of Neurochemistry,63, 785788. doi: 10.1046/j.1471-4159.1994.63020785.x

Jenike, M., \& Albert, M. (1984). The dexamethasone suppression test in patients with presenile and senile dementia of the Alzheimer's type. Journal of the American Geriatric Society, 32(6), 441-447.

Jha, A. P., Krompinger, J., \& Baime, M. J. (2007). Mindfulness training modifies subsystems of attention. Cognitive, Affective, \& Behavioral Neuroscience, 7, 109119. doi: 10.3758/CABN.7.2.109

Jha, A. P., Stanley, E. A., Kiyonaga, A., Wong, L., \& Gelfand, L. (2010). Examining the protective effects of mindfulness training on working memory capacity and affective experience. Emotion, 10, 54-64. doi: 10.1037/a0018438

Johansson, B., Bjuhr, H., \& Rönnbäck, L. (2012). Mindfulness-based stress reduction (MBSR) improves long-term mental fatigue after stroke or traumatic brain injury. Brain Injury, 26, 1621-1628. doi: 10.3109/02699052.2012.700082

Kabat-Zinn, J. (1982). An outpatient program in behavioral medicine for chronic pain patients based on the practice of mindfulness meditation: Theoretical considerations and preliminary results. General Hospital Psychiatry, 4, 33-47.

Kabat-Zinn, J. (1990). Full catastrophe living: Using the wisdom of your body and mind to face stress, pain, and illness. New York, NY: Delta Trade Paperbacks.

Kabat-Zinn, J., Massion, A. O., Kristeller, J., Peterson, L. G., Fletcher, K. E., Pbert, L., ... \& Santorelli, S. F. (1992). Effectiveness of a meditation-based stress reduction program in the treatment of anxiety disorders. American Journal of Psychiatry, 149(7), 936-943.

Lamar, M., Resnick, S. M., \& Zonderman, A. B. (2003). Longitudinal changes in verbal 
memory in older adults: Distinguishing the effects of age from repeat testing. Neurology, 60, 82-86. doi: 10.1212/WNL.60.1.82

Lamond, A. J., Depp, C. A., Allison, M., Langer, R., Reichstadt, J., Moore, D. J., ... \& Jeste, D. V. (2008). Measurement and predictors of resilience among communitydwelling older women. 43, 148-154. doi: 10.1016/j.jpsychires.2008.03.007

Landfield, P. Baskin, R., \& Pitler, T. (1981). Brain-aging correlates: Retardation by hormonal-pharmacological treatments. Science, 214, 581-584. doi: $10.1126 /$ science. 6270791

Lavretsky, H., Altstein, L., Olmstead, R. E., Ercoli, L. Riparetti-Brown, M., St. Cyr, N., \& Irwin, M. R. (2011). Complementary use of tai chi chih augments escitalopram treatment of geriatric depression: A randomized controlled trial. American Journal of Geriatric Psychiatry, 19, 839-850. doi: 10.1097/ JGP.0b013e31820ee9ef

LeDoux, J. E. (2000). The amygdala: A functional analysis (2 ${ }^{\text {nd }}$ ed.). J. P. Aggleton, (Ed.), Oxford: Oxford University Press

Lee, B. K., Glass, T. A., McAtee, M. J., Wand, G. S., Bandeen-Roche, K., Bolla, K. I., \& Schwartz, B. S. (2007). Associations of salivary cortisol with cognitive function in the Baltimore memory study. Archives of General Psychiatry, 64, 810-818. doi: 10.1001/archpsyc.64.7.810

Leresche, L. \& von Korff, M. R. (2003). Studying the epidemiology of temporomandibular disorders. In M. B. Max \& J. Lynn (Eds.), Symptom research: Methods and opportunities. Bethesda, MD: National Institute of Health.

Lewis, M., Morley, S., Windt, D. A., Hay, E., Jellema, P., Dziedzic, K., \& Main, C. J. (2010). 
Measuring practitioner/therapist effects in randomised trials of low back pain and neck pain interventions in primary care settings. European Journal of Pain, 14, 1033-1039. doi: 10.1016/j.ejpain.2010.04.002

Lewis, R. S., Nikolova, A., Chang, D. J., \& Weekes, N. Y. (2008). Examination stress and components of working memory. 11, 108-114. doi: 10.1080/ 10253890701535160

Lezak, M. D., Howieson, D. B., \& Loring, D. W. (2004). Neuropsychological assessment (4th ed.). New York: Oxford University Press.

Lie, C. H., Specht, K., Marshall, J. C., \& Fink, G. R. (2006). Using fMRI to decompose the neural processes underlying the Wisconsin Card Sorting Test. Neuroimage, 30, 1038-1049. doi: 10.1016/j.neuroimage.2005.10.031

Liston, C., McEwen, B. S., \& Casey, B. J. (2009). Psychosocial stress reversibly disrupts prefrontal processing and attentional control. Proceedings of the National Academy of Sciences, 106, 912-917. doi: 10.1073/pnas.0807041106

Luine, V., Villegas, M., Martinez, C., \& McEwen, B. S. (1994). Repeated stress causes reversible impairments of spatial memory performance. Brain Research, 639, 167-170. doi: 10.1016/0006-8993(94)91778-7

Lupien, S, Lecours, A. R., Schwartz, G., Sharma, S., Hauger, R. L., Meaney, M. J., \& Nair, N. P. V. (1995). Longitudinal study of basal cortisol levels in healthy elderly subjects: Evidence for sub-groups. Neurobiology of Aging, 17, 95-105. doi: 10.1037/0735-7044.113.3.420

Lupien, S. J., \& Lepage, M. (2001). Stress, memory, and the hippocampus: can't live with it, can't live without it. Behavioural Brain Research, 127, 137-158. doi: 10.1016/S0166-4328(01)00361-8 
Lupien, S. J., de Leon, M., de Santi, S., Convit, A., Tarshish, C., ... \& Meaney, M. J. (1998). Cortisol levels during human aging predict hippocampal atrophy and memory deficits. Nature Neuroscience, 1, 69-73. doi: 10.1038/271

Lupien, S. J., Maheu, F., Tu, M., Fiocco, A. J., \& Schramek, T. E. (2007). The effects of stress and stress hormones on human cognition: Implications for the field of brain and cognition. Brain and Cognition, 65, 209-237. doi: 10.1016/ j.bandc.2007.02.007

Lupien, S., Lecours, A. R., Lussier, I., Schwartz, G., Nair, N. P. V., \& Meaney, M. J. (1994). Basal cortisol levels and cognitive deficits in human aging. Journal of Neuroscience, 14(5I), 2893-2903.

Luz, C., Dornelles, F., Preissler, T., Collaziol, D., da Cruz, I. M., \& Bauer, M. E. (2003). Impact of psychological and endocrine factors on cytokine production of healthy elderly people. Mechanisms of Ageing and Development, 124, 887-895. doi: 10.1016/S0047-6374(03)00148-9

Lykins, E. L. B., Baer, R. A., \& Gottlob, L. R. (2012). Performance-based tests of attention and memory in long-term mindfulness meditators and demographically matched nonmeditators. Cognitive Therapy and Research, 36, 103-114. doi: 10.1007/s10608-010-9318-y

Lyons, D. M., Lopez, J. M., Yang, C., \& Schatzberg, A. F. (2000). Stress-level cortisol treatment impairs inhibitory control of behavior in monkeys. Journal of Neuroscience, 20, $7816-7821$.

Masliah, E., Mallory, M., Ge, N., Alford, M., Veinbergs, I., Roses, A.D. (1995). Neurodegeneration in the central nervous system of apoE-deficient mice. Experimental Neurology, 136, 107-122. doi: 10.1006/exnr.1995.1088 
Matousek, R. H., Dobkin, P. L., \& Pruessner, J. (2010). Cortisol as a marker for improvement in mindfulness-based stress reduction. Complementary Therapies in Clinical Practice, 16, 13-19. doi: 10.1016/j.ctcp.2009.06.004

Mausbach, B. T., Aschbacher, K., Mills, P. J., Roepke, S. K., von Känel, R., Patterson, T. L., ... Grant, I. (2008). A 5-year longitudinal study of the relationships between stress, coping, and immune cell beta(2)-adrenergic receptor sensitivity. Psychiatry Research, 160, 247-255. doi: 10.1016/j.psychres.2007.09.006

McEwen, B. S., de Leon, M. J., Lupien, S. J., \& Meaney, M. J. (1999). Corticosteroids, the aging brain and cognition. Trends in Endocrinology and Metabolism, 10, 92-96. doi: 10.1016/S1043-2760(98)00122-2

McEwen, B. S., \& Sapolsky, R. M. (1995). Stress and cognitive function. Current Opinion in Neurobiology, 5, 205-216. doi: 10.1016/0959-4388(95)80028-X

McEwen, B. S., \& Stellar, E. (1993). Stress and the individual: Mechanisms leading to disease. Archives of Internal Medicine, 153, 2093-2101. doi:10.1001/ archinte.1993.00410180039004

Meaney, M. J., \& Aitken, D. H. (1985). [ $\left.{ }^{3} \mathrm{H}\right]$ Dexamethasone binding in rat frontal cortex. Brain Research, 328, 176-180. doi:10.1016/0006-8993(85)91340-X

Meaney, M., Aitken, D., Bhatnager, S., Vanberkel, C., \& Sapolsky, R. (1988). Effects of neonatal handling on age-related impairments associated with the hippocampus. Science, 239, 766-769. doi: 10.1126/science.3340858

Mills, P. J., Ziegler, M. G., Patterson, T., Dimsdale, J. E., Hauger, R., Irwin, M., \& Grant, I. (1997). Plasma catecholamine and lymphocyte beta 2 -adrenergic receptor alterations in elderly Alzheimer caregivers under stress. Psychosomatic Medicine, 59(3), 251-256. 
Mitra, R., Jadhav, S., McEwen, B. S., Vyas, A., \& Chattarji, S. (2005). Stress duration modulates the spatiotemporal patterns of spine formation in the basolateral amygdala. Proceedings of the National Academy of Sciences of the United States of America, 102, 9371-9376. doi: 10.1073/pnas.0504011102

Mizoguchi, K., Ikeda, R., Shoji, H., Tanaka, Y., Marayuma, W., \& Tabira, T. (2009). Aging attenuates glucocorticoid negative feedback in rat brain. Neuroscience, 159, 259-270. doi: 10.1016/j.neuroscience.2008.12.020

Montorio, I., \& Izal, M. (1996). The Geriatric Depression Scale: A review of its development and utility. International Psychogeriatrics, 8, 103-112. doi: $10.1017 / \mathrm{S} 1041610296002505$

Morone, N. E., Lynch, C. S., Greco, C. M., Tindle, H. A., \& Weiner, D. K. (2008). “I felt like a new person." The effects of mindfulness meditation on older adults with chronic pain: Qualitative analysis of diary entries. Journal of Pain, 9, 841-848. doi: $10.1016 /$ j.pain.2008.04.003

Morone, N. E., Rollman, B. L., Moore, C. G., Qin, L., \& Weiner, D. K. (2009). A mind-body program for older adults with chronic low back pain: Results of a pilot study. Pain Medicine, 10, 1395-1407. doi: 10.1111\%2Fj.1526-4637.2009.00746.x

Moynihan, J. A., Klorman, R., Chapman, B. P., Duberstein, P. R., Brown, K. W., Krasner, M., ... \& Talbot, N. L. (2010). Mindfulness to improve elders' immune and health status. Psychoneuroimmunology, 24, S13. doi: http://dx.doi.org/10.1016/j.bbi.2010.07.041

Nithianantharajah, J., \& Hannan, A. J. (2009). The neurobiology of brain and cognitive reserve: Mental and physical activity as modulators of brain disorders. Progress in Neurobiology, 89, 369-382. doi: 10.1016/j.pneurobio.2009.10.001 
Olsson, T., Mohammed, A. J., Donaldson, L. F., Henriksson, B., \& Seckl, J. R. (1994). Glucocorticoid receptor and NGF1-A gene expression are induced in the hippocampus after environmental enrichment in adult rats. Molecular Brain Research, 23(4), 349-353.

Otte, C., Hart, S., Neylan, T. C., Marmar, C. R., Yaffe, K., \& Mohr, D. C. (2005). A metaanalysis of cortisol response to challenge in human aging: Importance of gender. Psychoneuroendocrinology, 30, 80-91. doi: 10.1016/

j.psyneuen.2004.06.002

Palta, P., Page, G., Piferi, R. L., Gill, J. M., Hayat, M. J., Connolly, A. B., \& Szanton, S. L. (2012). Evaluation of a mindfulness-based intervention program to decrease blood pressure in low-income African-American older adults. Journal of Urban Health, 89, 208-316. doi: 10.1007/s11524-01109654-6

Penley, J. A., Tomaka, J., \& Wiebe, J. S. (2002). The association of coping to physical and psychological health outcomes: A meta-analytic review. Journal of Behavioral Medicine, 25, 551-603. doi: 10.1023/A:1020641400589

Pinquart, M., \& Sörensen, S. (2003). Differences between caregivers and noncaregivers in psychological health and physical health: A meta-analysis. Psychology and Aging, 18, 250-267. doi: 10.1037/0882-7974.18.2.250

Pittenger, C., \& Duman, R. S. (2007). Stress, depression, and neuroplasticity: A convergence of mechanisms. Neuropsychopharmacology, 33, 88-109. doi: 10.1038/sj.npp.1301574

Poirier J., Davignon, J., Bouthillier, D., Kogan, S., Bertrand, P., \& Gauthier, S. (1993). Apolipoprotein E polymorphism and Alzheimer's disease. Lancet, 342, 697699. doi: 10.1016/0140-6736(93)91705-Q 
Porcelli, A. J., \& Delgado, M. R. (2009). Acute stress modulates risk taking in financial decision making. Psychological Science, 20, 278-283. doi: 10.1111/j.14679280.2009.02288.x

Pruessner, J. C., Baldwin, M. W., Dedovic, K., Renwick, R., Mahani, N. K., Lord, C., ... \& Lupien, S. (2005). Self-esteem, locus of control, hippocampal volume, and cortisol regulation in young and old adulthood. Neuroimage, 28, 815-826. doi: 10.1016/j.neuroimage.2005.06.014

Pruessner, J. C., Lord, C., Meaney, M. \& Lupien, S. (2004). Effects of self-esteem on agerelated changes in cognition and the regulation of the hypothalamic-pituitaryadrenal axis. Annals of the New York Academy of Science, 1032, 186-194. doi: 10.1196/annals.1314.017

Rasmusson, D. X., Zonderman, A. B., Kawas, C., \& Resnick, S. M. (1998). Effects of age and dementia on the Trail Making Test. The Clinical Neuropsychologist, 12, 169-178. doi: 10.1076/clin.12.2.169.2005

Raz, N., Gunning-Dixon, F. M., Head, D., Dupuis, J. H., \& Acker, J. D. (1998). Neuroanatomical correlates of cognitive aging: Evidence from structural magnetic resonance imaging. Neuropsychology, 12, 95-114. doi: 10.1037/08944105.12.1.95

Reitan, R., \& Wolfson, D. (1993). The Halstead-Reitan neuropsychological test battery: Theory and clinical interpretation. Tucson, AZ: Neuropsychology Press.

Richmond, L. L., Morrison, A. B., Chein, J. M., \& Olson, I. R. (2011, June 27). Working memory training and transfer in older adults. Psychology and Aging, 26, 813822. doi: $10.1037 / \mathrm{a} 0023631$

Roozendaal, B., McEwen, B. S., \& Chattarji, S. (2009). Stress, memory and the 
amygdala. Nature Reviews: Neuroscience, 10, 423-433. doi: 10.1038/nrn2651

Roselli, F., Tartaglione, B., Federico, F., Lepore, V., Defazio, G., \& Livrea, P. (2009). Rate of MMSE score change in Alzheimer's disease: Influence of education and vascular risk factors. Clinical Neurology and Neurosurgery, 111, 327-330. doi: 10.1016/j.clineuro.2008.10.006

Rosenberg, M. (1965). Society and the adolescent self-image. Princeton, NJ: Princeton University Press.

Rubinow, M. J., Drogos, L. L., \& Juraska, J. M. (2009). Age-related dendritic hypertrophy and sexual dimorphism in rat basolateral amygdala. Neurobiology of Aging, 30, 137-146. doi: 10.1016/j.neurobiolaging.2007.05.006

Sapolsky, R. M. (1992). Stress, the aging brain and the mechanisms of neuron death. Cambridge, Massachusetts: MIT Press.

Sapolsky, R. M. (1999). Glucocorticoids, stress, and their adverse neurological effects: Relevance to aging. Experimental Gerontology, 34, 721-732. doi: 10.1016/S0531-5565(99)00047-9

Sapolsky, R. M., Krey, L. C., \& McEwen, B. S. (1984). Stress down-regulates corticosterone receptors in a site specific manner in the brain. Endocrinology 114, 287-292. doi: http://dx.doi.org/10.1210/endo-114-1-287

Sapolsky, R. M., Krey, L. C., \& McEwen, B. S. (1986). The neuroendocrinology of stress and aging: The glucocorticoid cascade hypothesis. Endocrine Reviews, 7, 284301.

Schulz, R., \& Martire, L. M. (2004). Family caregiving of persons with dementia: Prevalence, health effects, and support strategies. The American Journal of Geriatric Psychiatry, 12, 240-249. doi: 10.1097/00019442-200405000-00002 
Seals, D. R., \& Esler, M. D. (2000). Human ageing and the sympathoadrenal system. Journal of Physiology, 528, 407-417. doi: 10.1111/j.1469-7793.2000.00407.x

Seeman, T. E., McEwen, B. S., Singer, B. H., Albert, M. S., \& Rowe, J. W. (1997). Increase in urinary cortisol excretion and memory declines: MacArthur studies on successful aging. The Journal of Clinical Endocrinology \& Metabolism, 82, 24582465. doi: $10.1210 / j c .82 .8 .2458$

Segal, M., \& Bloom, F. E. (1976). The action of norepinephrine in the rat hippocampus: The effects of locus coeruleus stimulation on evoked hippocampal unit activity. Brain Research, 107, 513-525. doi: 10.1016/0006-8993(76)90141-4

Segal, Z. J., Williams, M. G., \& Teasdale, J. D. (2002). Mindfulness based cognitive therapy for depression: A new approach to preventing relapses. New York: Guildford Press.

Segovia, G., del Arco, A., De Blas, M., Garrido, P., \& Mora, F. (2008). Effects of an enriched environment on the release of dopamine in the prefrontal cortex produced by stress and on working memory during aging in the awake rat. Behavioural Brain Research, 187, 304-311. doi: 10.1016/j.bbr.2007.09.024

Shapiro, S. L., Bootzin, R. R., Figueredo, A. J., Lopez, A. M., \& Schwartz, G. E. (2003). The efficacy of mindfulness-based stress reduction in the treatment of sleep disturbance in women with breast cancer: An exploratory study. Journal of Psychosomatic Research, 54, 85-91. doi: 10.1016/S0022-3999(02)00546-9

Shapiro, S. L., Brown, K. W., \& Biegel, G. M. (2007). Teaching self-care to caregivers: Effects of mindfulness-based stress reduction on the mental health of therapists in training. Training and Education in Professional Psychology, 1, 105-115. doi: 10.1037/1931-3918.1.2.105 
Shapiro, S. L., Carlson, L. E., Astin, J. A., \& Freedman, B. (2006). Mechanisms of mindfulness. Journal of Clinical Psychology, 62, 373-386. doi: 10.1002/jclp.20237

Skosnik, P. D., Chatterton Jr., R. T., Swisher, T., \& Park, S. (2000). Modulation of attentional inhibition by norepinephrine and cortisol after psychological stress. International Journal of Psychophysiology, 36, 59-68. doi:

10.1016/S0167-8760(99)00100-2

Speca, M., Carlson, L. E., Goodey, E., \& Angen, M. (2000). A randomized, waitlist controlled clinical trial: The effect of a mindfulness meditation-based stress reduction program on mood and symptoms of stress in cancer outpatients. Psychosomatic Medicine, 62(5), 613-622.

Starkman, M. N., Gebarski, S. S., Berent, S., \& Schteingart, D. E. (1992). Hippocampal formation volume, memory dysfunction, and cortisol levels in patients with Cushing's syndrome. Biological Psychiatry, 32, 756-765. doi: 10.1016/00063223(92)90079-F

Statistics Canada. (2010). Annual Demographic Estimates: Canada, Provinces and Territories. (Catalogue number 91-215-XWE). Retrieved March 10, 2013 from Statistics Canada: http://www.statcan.gc.ca/pub/91-215-x/91-215x2012000-eng.pdf

Steinberg, B. A., Bieliauskas, L. A., Smith, G. E., \& Ivnik, R. J. (2005). Mayo's older Americans normative studies: Age- and IQ-adjusted norms for the Trail-Making Test, the Stroop test, and MAE controlled oral word association test. The Clinical Neuropsychologst, 19, 329-377. doi: 10.1080/13854040590945210

Stroop, John Ridley (1935). Studies of interference in serial verbal reactions. Journal 
of Experimental Psychology, 18, 643-662. doi: 10.1037/h0054651

Stuss, D. T., Bisschop, S. M., Alexander, M. P., Levine, B., Katz, D., \& Izukawa, D. (2001). The Trail Making Test: A study in focal lesion patients. Psychological Assessment, 13, 230-239. doi: 10.1037//1040-3590.13.2.230

Svec, F. (1997). Ageing and adrenal cortical function. Baillière's Clinical Endocrinology and Metabolism, 11, 271-287. doi: 10.1016/S0950-351X(97)80287-X

Swanwick, G. R. J., Kirby, M., Bruce, I., Buggy, F., Coen, R. F., Coakley, D., \& Lawlor, B. A. (1998). Hypothalamic-pituitary-adrenal axis dysfunction in Alzheimer's disease: Lack of association between longitudinal and cross-sectional findings. American Journal of Psychiatry, 155(2), 286-289.

Sztainberg, Y., Kuperman, Y., Tsoory, M., Lebow, M., \& Chen, A. (2010). The anxiolytic effect of environmental enrichment is mediated via amygdalar CRF receptor type 1. Molecular Psychiatry, 15, 905-917. doi: 10.1038/mp.2009.151

Thierry, A. M., Javoy, F., Glowinsky, J., \& Kety, S. S. (1968). Effects of stress on the metabolism of norepinephrine, dopamine, and serotonin in the central nervous system of the rate: Modification of norepinephrine turnover. Journal of Pharmacological \& Experimental Therapy, 163(1), 163-171.

Tombaugh, T. N. (2004). Trail Making Test A and B: Normative data stratified by age and education. Archives of Clinical Neuropsychology, 19, 203-214. doi: 10.1016/S0887-6177(03)00039-8

Tombaugh, T. N., Kozak, J., \& Rees, L. (1999). Normative data stratified by age and education for two measures of verbal fluency: FAS and animal naming. Archives of Clinical Neuropsychology, 14, 167-177. doi: 10.1016/S0887-6177(97)000954 
Tombaugh, T. N., \& McIntyre, N. J. (1992). The mini-mental state examination: A comprehensive review. Journal of the American Geriatrics Society, 40(9), 922935.

Thompson, L. W., Gallagher, D., \& Breckenridge, J. S. (1987). Comparative effectiveness of psychotherapies for depressed elders. Journal of Consulting and Clinical Psychology, 55, 385-390. doi: 10.1037/0022-006X.55.3.385

Uno, H., Tarara, R., Else, J. G., Suleman, M. A., \& Sapolsky, R. M. (1989). Hippocampal damage associated with prolonged and fatal stress in primates. Journal of Neuroscience, 9(5), 1705-1711.

Vedhara, K., Cox, N. K., Wilcock, G. K., Perks, P., Hunt, M., Anderson, S., . . \& Shanks, N. M. (1999). Chronic stress in elderly carers of dementia patients and antibody response to influenza vaccination. Lancet, 353, 627-631. doi: 10.1016/S01406736(98)06098-X

Watanabe, Y., Gould, E., \& McEwen, B. S. (1992). Stress induces atrophy of apical dendrites oh hippocampal CA3 pyramidal neurons. Brain Research 2, 341- 345. doi: 10.1016/0006-8993(92)91597-8

Weaver, I. C. G., Cervoni, N., Champagne, F. A., D’Alessio, A. C., Sharma, S., Seckl, J. R., ... \& Meaney, M. J. (2004). Epigenetic programming by maternal behavior. Nature Neuroscience, 7, 847-854. doi: 10.1038/nn1276

Webb, C. A., DeRubeis, R. J., \& Barber, J. P. (2010). Therapist adherence/competence and treatment outcome: A meta-analytic review. Journal of Consulting and Clinical Psychology, 78, 200-211. doi: 10.1037/a0018912

Wenk-Sormaz, H. (2005). Meditation can reduce habitual responding. Advances in Mind-Body Medicine, 21(3-4), 33-49. 
Wesson, J., Clemson, L., Brodaty, H., Lord, S., Taylor, M., Gitlin, L., \& Close, J. (2013). A feasibility study and pilot randomised trial of a tailored prevention program to reduce falls in older people with mild dementia. BMC Geriatrics, 13, 89-101. doi: 10.1186/1471-2318-13-89

West, A., \& Spring, B. (2002). Randomized controlled trials. Retrieved from http://www.ebbp.org/course_outlines/randomized_controlled_trials/

Wilksch, S. M. (2013). School-based eating disorder prevention: A pilot effectiveness trial of teacher-delivered Media Smart. Early Intervention in Psychiatry, 1, 1-8. doi: 10.1111/eip.12070

Wilson, R. S., Bennett, D. A., Beckett, L. A., Morris, M. C., Gilley, D. W., Bienias, J. L., ... \& Evans, D. A. (1999). Cognitive activity in older persons from a geographically defined population. Journal of Gerontology: Psychological Sciences, 54B, 155160. doi: 10.1093/geronb/54B.3.P155

Wilson, R. S., Mendes de Leon, C. F., Barnes, L. L., Schnider, J. A., Bienias, J. L., Evans, D. A., \& Bennett, D. A. (2002). Participation in cognitively stimulating activities and risk of incident Alzheimer's disease. Journal of the American Medical Association, 287, 742-748. doi: 10.1001/jama.287.6.742

Wiltsey-Stirman, S. W., Monson, C. M., \& Resick, P. (2013). Cognitive Processing Therapy: Therapist Adherence and Competence Protocol. Unpublished manuscript.

Wood, J. G., Rogina, B., Lavu, S., Howitz, K., Helfand, S. L., Tatar, M., \& Sinclair, D. (2004). Sirtuin activators mimic caloric restriction and delay ageing in metazoans. Nature, 430, 686-689. doi: 10.1038/nature02789

Woolfolk, R. L., Lehrer, P. M., McCann, B. S., \& Rooney, A. J. (1982). Effects of 
progressive relaxation and meditation on cognitive and somatic manifestations of daily stress. Behaviour Research and Therapy, 20(5), 461-467.

Woolley, C. S., Gould, E., \& McEwen, B. S. (1990). Exposure to excess glucocorticoids alters dendritic morphology of adult hippocampal pyramidal neurons. Brain Research, 531, 225-231. doi: 10.1016/0006-8993(90)90778-A

Yaffe, K., Fiocco, A. J., Lindquist, K., Vittinghoff, E., Simonsick, E. M., Newman, A. B., ... \& Harris, T. B. (2009). Predictors of maintaining cognitive function in older adults: The Health ABC Study. Neurology, 72, 2029-2035. doi:

10.1212/WNL.0b013e3181a92c36

Yesavage, J. A., Brink, T. L., Rose, T. L., Lum, O., Huang, V., Adey, M., \& Leirer, V. O. (1983). Development and validation of a geriatric depression screening scale: A preliminary report. Journal of Psychiatric Research, 17, 37-49. doi: 10.1016/0022-3956(82)90033-4,

Young, L., \& Baime, M. (2010). Mindfulness-based stress reduction: Effect on emotional distress in older adults. Complementary Health Practice Review, 15, 59-64. doi: $10.1177 / 1533210110387687$

Zawia, N. H., Lahiri, D. K., \& Cardozo-Pelaez, F. (2009). Epigenetics, oxidative stress and Alzheimer's Disease. Free Radical Biology \& Medicine, 46, 1241-1249. doi: 10.1016/j.freeradbiomed.2009.02.006

Zeidan, F., Johnson, S. K., Diamond, B. J., David, Z., \& Goolkasian, P. (2010). Mindfulness meditation improves cognition: Evidence of brief mental training. Consciousness and Cognition, 19, 597-605. doi: 10.1016/ j.concog.2010.03.014

Zetzsche, T., Frodl, T., Preuss, U. W., Schmitt, G., Seifert, D., Leinsinger, G., ... \& Meisenzahl, E. M. (2006). Amygdala volume and depressive symptoms in 
patients with borderline personality disorder. Biological Psychiatry, 60, 302310. doi: 10.1016/j.biopsych.2005.11.020 